\title{
Understanding the Influence of Surface Oxygen Groups on the Electrochemical Behavior of Porous Carbons as Anodes for Lithium-Ion Batteries
}

Marie-Laure C. Piedboeuf ${ }^{1 \#}$, Nathalie Job ${ }^{1}$, Abdelhafid Aqil ${ }^{2}$, Yan Busby ${ }^{3,4}$, Vanessa Fierro $^{5}$, Alain Celzard ${ }^{5}$, Christophe Detrembleur ${ }^{2}$, Alexandre F. Léonard ${ }^{1 *}$

${ }^{1}$ University of Liège, Department of Chemical Engineering - Nanomaterials, Catalysis,

Electrochemistry (NCE) - B6a, Sart-Tilman, B-4000 Liège, Belgium

${ }^{2}$ University of Liège, Center for Education and Research on Macromolecules (CERM) - B6a, Sart-Tilman, B-4000 Liège, Belgium

${ }^{3}$ University of Namur, Namur Institute of Structured Matter, B-5000 Namur, Belgium

${ }^{4}$ French-German Research Institute of Saint-Louis, Nanomatériaux pour les Systèmes Sous Sollicitations Extrêmes (NS3E), 68301 Saint-Louis, France

${ }^{5}$ University of Lorraine, Institut Jean Lamour, UMR CNRS, ENSTIB, 27 Rue Philippe Séguin, BP 21042, F-88051, France

*Corresponding author. Tel: +32 4366 3579. E-mail: alexandre.leonard@ $@$ uliege.be (A.F. Leonard). \#Present address: AC\&CS - CRM GROUP, Allée de l'Innovation 1, B - 4000 Liege (Belgium). 


\section{Abstract}

The present study elucidates the role of surface oxygen functional groups on the electrochemical behavior of porous carbons when used as anodes for $\mathrm{Li}$-ion batteries. To achieve this objective, a carbon xerogel (CX) obtained by pyrolysis of a resorcinol-formaldehyde gel was modified by different post-synthesis treatments in order to modulate its surface chemistry while maintaining its external surface constant. Various surface modifications were obtained by oxidation in air, insitu polymerization of dopamine and, finally, by grafting of a polyethylene oxide layer on the polydopamine coating. While oxidation in air did not affect the pore texture of the CX, modifications by coating techniques substantially decreased the micropore fraction. Detailed electrochemical characterizations of the materials processed as electrodes were performed by capacitance measurements and galvanostatic cycling. Surface chemistry results, by X-ray photoelectron spectroscopy, show that the accessibility and the capacity increase when carbonyl $(\mathrm{R}-\mathrm{C}=\mathrm{O})$ groups are formed on the $\mathrm{CX}$, but not with oxides and hydroxyls. The amount of surface carbonyls, and in particular aldehyde $(\mathrm{O}=\mathrm{CH})$ groups, is found as the key parameter since it is directly correlated with the modified CX electrochemical behavior. Overall, the explored surface coatings tend to reduce the micropore volume and add mainly hydroxyl functional groups but hardly change the $\mathrm{Li}^{+}$insertion/de-insertion capacities, while oxidation in air adds carbonyl groups, increasing the $\mathrm{Li}^{+}$ions storage capacity thanks to an improved accessibility to the carbon network, which is not caused by any textural change.

\section{Keywords}

Carbon xerogel, Li-ion battery, surface oxygen groups, electrolyte accessibility, polydopamine 


\section{Introduction}

Li-ion batteries are extensively used in various fields such as automotive or portable electronics [1]. In such kind of electrochemical devices, the operating principle is based on the shuttling of $\mathrm{Li}^{+}$ions between intercalation materials at the cathode and the anode. In fact, the interface between the surface of the electrode material and the electrolyte, made up of dissolved $\mathrm{Li}^{+}$salts, plays a key role for the insertion/de-insertion reactions of $\mathrm{Li}^{+}$ions. For this reason, the surface chemistry of the active material of the electrode is an important feature to be taken into account [2] as it could mainly affect the wettability of the electrode and/or act on the formation of the solid electrolyte interface (SEI) during the first charge-discharge cycle [3]. So far, graphite is mainly used as an anode material for Li-ion batteries, but better performance can be expected when using other carbons, such as hard carbons for instance. Indeed, the presence of an inherent porosity in hard carbons could explain an extension of the cycling life upon repetitive swelling and shrinking during the insertion and de-insertion of $\mathrm{Li}^{+}$ions, respectively. Although increased capacities could also be reached due to the presence of additional accommodation sites for $\mathrm{Li}^{+}$ions, the practical use of porous carbons as anode materials remains precluded due to the important irreversible losses that occur during the first charge-discharge cycle [4,5]. A better and deeper understanding of the effect of the surface chemistry of porous carbons on these losses could help improve their performance.

The surface of disordered carbon materials is characterized by a high polarizability and an amphoteric nature. The influence of heteroatoms such as surface oxygen groups (SOG) and surface nitrogen groups (SNG) on the electrochemical properties of anodes for Li-ion batteries has been described in previous studies [6-10]. However, the outcomes are often contradictory. As an example, when an oxidation treatment is applied to a carbon fiber material, the presence of SOG induces an increase in irreversible losses due to the formation of a thicker SEI [11]. Nevertheless, the same functionalization carried out on carbon nanotubes leads to a decrease in irreversible losses, a better handling and a lower mechanical degradation [12]. The review article by Collins 
et al. reports sparse literature on this topic and, from a general point of view, there is still no clear evidence on how the presence and density of SOG and SNG could affect the insertion and deinsertion of $\mathrm{Li}^{+}$ions within carbon-based anodes [3]. Studies on the influence of these surface functional groups on the electrochemical behavior of porous carbons when used as anode for Liion batteries are of paramount interest to understand and improve their performance.

Different routes are possible to increase the amount of SOG on carbon materials. One consists in using oxidizers in the liquid phase, such as hydrogen peroxide $\left(\mathrm{H}_{2} \mathrm{O}_{2}\right)$, nitric acid $\left(\mathrm{HNO}_{3}\right)$ or ammonium persulfate $\left(\left(\mathrm{NH}_{4}\right)_{2} \mathrm{~S}_{2} \mathrm{O}_{8}\right)$. The second implies a dry-phase treatment under a flow of oxidizing gas such as oxygen $\left(\mathrm{O}_{2}\right)$, ozone $\left(\mathrm{O}_{3}\right)$ or nitrous oxide $\left(\mathrm{N}_{2} \mathrm{O}\right)$ [13-15]. Alternatively, lowpressure plasmas have been applied to introduce oxygen and nitrogen functional groups [16-17]. Generally, these methods lead to a heterogeneous distribution of acidic and basic oxygen functional groups [3]. Carbon xerogels have been efficiently functionalized by immersion in an aqueous solution of $\mathrm{HNO}_{3}$ or by oxidation under air flow, in order to prepare carbon supports for catalytic applications [18-22].

An alternative approach to modify the surface chemistry of carbon materials is to coat their porous surface using various precursors. Surface functionalities such as lactones and quinones can be introduced by coating with polydopamine. Indeed, the in-situ polymerization of dopamine over a porous carbon substrate can generate a highly adherent layer. The latter strategy has been used for the functionalization of carbon nanotubes $[23,24]$ or graphite and, when the as-coated graphite was used as anode for Li-ion batteries, the thermal stability increased and the rate-performance was improved by facilitating the interfacial transport of $\mathrm{Li}^{+}$ions along the $\mathrm{SEI}$ [25]. In addition to an easy self-assembling polymerization process of the dopamine monomers in water, this strategy also offers the advantage of introducing many functional groups (amines, imines and catechols). The latter can in fact serve as anchoring points for covalent grafting of polyethylene oxide functionalized by thiol groups (PEO-SH) via Michael addition [26]. Indeed, the presence of these PEO groups might: (i) limit the degradation of the electrolyte at the surface of the electrode and 
promote the formation of a thin and robust SEI layer [27]; and (ii) advantageously serve as preferential interface for the development of batteries with solid electrolytes based on PEO.

All these treatments are accompanied by variations in the textural properties and quite often in the external surface area of the carbon materials, which have a determining effect on the electrochemical performance of Li-ion batteries [28]. This research work is devoted to: (i) the study of the effects of various post-synthesis treatments on the modulation of the surface chemistry of porous carbon xerogels $(\mathrm{CX})$; and (ii) the evaluation of the influence of these effects on the electrochemical behavior of CX when used as anodes for Li-ion batteries. For this purpose, a CX with a homogeneous macropore size of $80 \mathrm{~nm}$ has been chosen as a substrate to undergo multiple post-synthesis treatments allowing the modulation of its surface chemistry. The surface chemistry of the resulting samples was characterized by X-ray photoelectron spectroscopy (XPS) and the overall bulk composition was checked by elemental analysis (EA). Since the surface modification may also affect the textural properties of the pristine CX material, an extensive characterization of their texture was performed by gas adsorption and mercury intrusion measurements. The materials were applied on current collectors for electrochemical characterization by using a waterbased pathway in presence of xanthan gum as a binder that preserves the pore texture of the starting materials [29] contrary to PVDF- and NMP-based classical routes [30]. Finally, the effect of these treatments on the wettability of the materials by the electrolyte and on the electrochemical behavior as anode for $\mathrm{Li}$-ion batteries was investigated. 


\section{Materials and methods}

\subsection{Synthesis of the carbon xerogel}

The pristine carbon xerogel (CX) was prepared following the process described by Job et al. [31]. A 35 wt. \% aqueous solution of resorcinol (Merck) was prepared and the $\mathrm{pH}$ was set by addition of solid sodium carbonate. A 37 wt. \% solution of formaldehyde stabilized by 10-15\% methanol (Sigma-Aldrich) was then added in a resorcinol/formaldehyde molar ratio equal to $1: 2$, and the mixture was magnetically stirred for $1 \mathrm{~h}$. The dilution ratio $D=$ water/reactants molar ratio was fixed at 5.7 and the resorcinol to carbonate molar ratio was chosen equal to 2000 . The obtained homogeneous gel precursor solution was then sealed in a $1 \mathrm{~L}$ autoclavable glass flask and aged for 3 days at $85^{\circ} \mathrm{C}$. Drying was then performed by placing the gel in a vacuum oven $(2 \mathrm{kPa})$ at $60^{\circ} \mathrm{C}$ for $12 \mathrm{~h}$ and at $150^{\circ} \mathrm{C}$ for $30 \mathrm{~h}$. The resulting dry xerogel was then ground using a Fritsch planetary mill (Mono Mill P6) in agate jars with $1 \mathrm{~cm}$ diameter balls following the procedure described in a previous work, affording homogenous and reproducible particle sizes [32]. The obtained powder was then put in a quartz boat and introduced in a ceramic tubular furnace to undergo a pyrolysis step at $900^{\circ} \mathrm{C}$, leading to the carbon xerogel (CX). The pyrolysis was performed under nitrogen (Air Liquide Alphagaz 1, flow rate 0.004 mol.min ${ }^{-1}$ ) just before coating current collectors or other post-synthesis treatments. The following temperature profile was used: (1) ramp at $1.7^{\circ} \mathrm{C} \cdot \mathrm{min}^{-1}$ to $150^{\circ} \mathrm{C}$ and hold for $15 \mathrm{~min}$; (2) ramp at $5^{\circ} \mathrm{C} \cdot \mathrm{min}^{-1}$ to $400^{\circ} \mathrm{C}$ and hold for $60 \mathrm{~min}$; (3) ramp at $5^{\circ} \mathrm{C} \cdot \mathrm{min}^{-1}$ to $900^{\circ} \mathrm{C}$ and hold for $120 \mathrm{~min}$; and (4) natural cooling to room temperature. The reference sample (CX-Ref) denotes the CX pyrolyzed at $900^{\circ} \mathrm{C}$ without further treatment.

\subsection{Surface modification treatments}

\subsubsection{CX oxidation in air}

Oxidation under an air flow was performed in a tubular furnace connected to a supply of nitrogen and air via a three-way valve, allowing to switch between the two atmospheres. $2 \mathrm{~g}$ of powdery $\mathrm{CX}$ were introduced in the furnace and heated up to $350^{\circ} \mathrm{C}$ under nitrogen atmosphere (Air Liquide 
Alphagaz 1, flow rate $\left.0.004 \mathrm{~mol} \cdot \mathrm{min}^{-1}\right)$. After stabilization of the temperature, the atmosphere was switched to air (Air Liquide Alphagaz 1, flow rate 0.004 mol.min ${ }^{-1}$ ) for 1 or $3 \mathrm{~h}$. Subsequent cooling was done under nitrogen atmosphere. The corresponding samples are denoted CX-Ox1 and $\mathrm{CX}-\mathrm{Ox} 3$, respectively.

\subsubsection{CX modification with polydopamine}

This treatment was performed by bringing the CX powder directly into contact with an aqueous solution of dopamine, followed by polymerization. The solvent used for this treatment was a TRIS buffer (1.21 g.L $\mathrm{L}^{-1}$, pH 8.5, Sigma-Aldrich, > $\left.99.8 \%\right)$. The synthesis was realized in six different flasks (Falcon). In each of them, $0.3 \mathrm{~g}$ of CX powder was dispersed in $40 \mathrm{~mL}$ of TRIS buffer. These suspensions were placed under vacuum in a dryer connected to a vacuum ramp for $2 \mathrm{~h}$ in order to eliminate the air present inside the pores and to allow a good penetration of the solvent in the CX porosity. $40 \mathrm{mg}$ of dopamine (Sigma-Aldrich, H8502) were then added to each flask such as to reach a concentration of $1 \mathrm{mg} \cdot \mathrm{mL}^{-1}$. The mixture was then stirred for $1 \mathrm{~h}$ with a rotary mixer (Labinco, speed: 5), followed by a vacuum filtration to recover the six modified CX powders in a single sample. The powder was then washed three times with $100 \mathrm{~mL}$ of ultra-pure water (MilliQ). The initial filtrate displayed a pink color typical of the presence of polydopamine in solution while the water after washing steps was colorless. Finally, the powder was dried in an oven at $80^{\circ} \mathrm{C}$, under vacuum $(2 \mathrm{kPa})$, for $16 \mathrm{~h}$. This sample is denoted CX-Dopa hereafter.

\subsubsection{CX modification with polydopamine followed by PEO grafting}

The first step of this treatment was to reproduce the same synthesis as that described in section 2.2.2. After filtration and washing, the powder was directly brought into contact with $240 \mathrm{~mL}$ of an aqueous solution of polyethylene oxide functionalized by a thiol group (PEO-SH) in a TRIS buffer $\left(2 \mathrm{mg} \cdot \mathrm{mL}^{-1}\right)$. Polydopamine reacts with the thiol groups through Michael addition reaction to covalently graft the PEO-SH. This suspension was then divided equally and placed in six different flasks for a rotary mixing lasting $18 \mathrm{~h}$. These suspensions were then put together, filtered under vacuum and washed three times with $100 \mathrm{~mL}$ ultra-pure water (Milli-Q). The initial filtrate 
was yellow and some foam was observed during the washing step, while the water after washing was colorless. Finally, the powder was dried in an oven, at $80^{\circ} \mathrm{C}$ under vacuum $(2 \mathrm{kPa})$, for $52 \mathrm{~h}$. This sample is denoted CX-Dopa+PEO.

\subsection{Surface chemistry and bulk composition}

The surface chemistry of the samples was studied by X-ray photoelectron spectroscopy (XPS), performed with a spectrometer Escalab $250 \mathrm{Xi}$ by Thermo Scientific, operating with a monochromatic $\mathrm{Al} \mathrm{K}_{\alpha}$ radiation $(1486.6 \mathrm{eV})$, on a $500 \times 500 \mu \mathrm{m}$ spot area and a flood gun for charge compensation. The surface elemental composition (atomic \%) was directly evaluated on survey scans from C1s, O1s, N1s, S2p. Chemical functional groups such as oxides (C-O-C), hydroxides $(\mathrm{C}-\mathrm{OH})$, carbonyls $(\mathrm{R}-\mathrm{C}=\mathrm{O})$ and carboxylic acid $(\mathrm{O}-\mathrm{C}=\mathrm{O})$ were identified from the peak analysis of $\mathrm{O} 1 \mathrm{~s}$ and $\mathrm{C} 1 \mathrm{~s}$ high-resolution spectra [33-35]. The binding energy calibration was made on the $\mathrm{C} 1 \mathrm{~s}$ main peak at $285 \mathrm{eV}$. In coated samples, the quantification of chemical groups was derived from the peak analysis of O1s spectra because the peak-fitting of $\mathrm{C} 1 \mathrm{~s}$ spectra was less accurate due to the overlap between R-CO, R-CN and R-CS chemical components. Elemental analysis (EA) was performed in an Elementar Vario EL Cube analyzer for determining carbon, hydrogen, oxygen, nitrogen and sulfur contents in the bulk of the materials

\subsection{Preparation and characterization of electrodes}

After grinding, pyrolysis and post-synthesis modifications, the materials were processed into electrodes. The final powders were stored in a glove box under argon atmosphere (MBraun) before coating to avoid any possible modification of the surface chemistry. CX (88 wt. \%) and xanthan gum (Sigma-Aldrich, binder, 12 wt. \%) were mixed in ultra-pure water to form a homogeneous slurry [36]. This ink was then sprayed manually (Harder \& Steenbeck Evolution Silverline 2) on pre-weighed stainless steel disks (diameter $15.5 \mathrm{~mm}$, MTI corporation, Stainless steel 304, thickness $0.5 \mathrm{~mm}$ ). After drying at room temperature for $1 \mathrm{~h}$, at $60^{\circ} \mathrm{C}$ for $16 \mathrm{~h}$ and at $120^{\circ} \mathrm{C}$ for 3 $\mathrm{h}$ under vacuum, these electrodes were introduced into the glove box. The excess of dry ink sprayed next to the electrodes on the protecting aluminum foil was scratched from the support and 
recovered, to obtain a powdery active material-binder composite that displays the same textural parameters as those of the electrodes.

\subsection{Pore texture and particle size characterization}

The pore texture of the CX samples was characterized by nitrogen adsorption-desorption as well as by mercury intrusion porosimetry. The adsorption-desorption isotherms of nitrogen and carbon dioxide were measured at $-196^{\circ} \mathrm{C}$ and $0^{\circ} \mathrm{C}$, respectively, using a Micromeritics ASAP 2420 automatic device (Micromeritics, Norcross, USA). The samples were degassed overnight at $80^{\circ} \mathrm{C}$ under vacuum (133 Pa) for $60 \mathrm{~h}$ prior to the measurements. The BET area, $A_{\mathrm{BET}}$, was calculated using the Brunauer-Emmett-Teller (BET) equation, the adsorption data being taken in the adequate range of relative pressure $\left(\mathrm{P} / \mathrm{P}^{0}\right)$, taking into account the Rouquerol criterion [37]. The micropore volumes (volumes of pores of width lower than $2 \mathrm{~nm}$ ) were determined by the DubininRadushkevich method [38] applied to $\mathrm{N}_{2}$ and $\mathrm{CO}_{2}$ adsorption data and labeled $V_{\mathrm{DR}, \mathrm{N} 2}$ and $V_{\mathrm{DR}}$, $\mathrm{CO} 2$, respectively. The evolution of the microporosity of selected samples was further investigated by fitting simultaneously $\mathrm{N}_{2}$ and $\mathrm{CO}_{2}$ adsorption isotherms, using a non-local density functional theory (2D-NLDFT-HS) model assuming slit-shaped pores and heterogeneous surface [39-40], with the SAIEUS ${ }^{\circledR}$ software (Micromeritics, Norcross, USA). The application of the 2D-NLDFTHS model allowed calculating the specific surface area, $S_{\mathrm{NLDFT}}$, the micropore volume, $V_{\text {micro, }}$, and the pore size distribution (PSD). The external surface area $S_{\text {ext }}$ was calculated as $S_{\text {ext }}=S_{\mathrm{NLDFT}}$ $S_{\text {micro, }}$ where $S_{\text {micro }}$ is the cumulated surface area up to $2 \mathrm{~nm}$.

Since the CX samples comprise macropores, the gas adsorption techniques are not sufficient to get a complete assessment of the textural properties. For this reason, mercury porosimetry was performed on a Quantachrome Poremaster 60 in a pressure range between 0.01 and $400 \mathrm{MPa}$. The analysis of the obtained mercury intrusion data allowed determining the pore volume, $V_{\mathrm{Hg}}$, as well as the pore size distribution for pores larger than $3.8 \mathrm{~nm}$ in diameter. The latter was calculated using the Washburn equation [41]. 
Since powders are analyzed, it is necessary to distinguish the volume of intraparticular intrusion, $V_{\text {int }}$, from the total volume of mercury, $V_{\mathrm{Hg}}$, which takes into account the intergranular voids between particles. The retention of the porous properties of the bare powders in the final active material-binder composites was checked by nitrogen adsorption-desorption and mercury intrusion analyzes.

The particle size distributions of the ground powders were obtained using laser diffraction with a Mastersizer 2000 (Malvern Instruments) in wet mode (Hydro2000). Prior to grain size distribution measurements, the samples were dispersed in water using high-intensity sonication (Hielsher, UP400S). The sample preparation method was described elsewhere [32]. The particle size distributions were obtained from the raw data by mathematical processing, assuming a spherical geometry of the particles.

\subsection{Electrochemical characterization}

The electrochemical measurements were carried out in CR2032 coin cells, where the carbon material acted as the positive electrode and a Li-metal disk as the negative, reference and counter electrode. A Celgard ${ }^{\circledR}$ separator impregnated with $80 \mu \mathrm{L}$ of LP71 electrolyte $\left(1\right.$ mol.L $\mathrm{L}^{-1} \mathrm{LiPF}_{6}$ in EC:DEC:DMC 1:1:1) was placed in between. The cell was assembled in a glove box (MBraun) filled with Ar. Charge-discharge cycles were recorded at C/10 between 0.005 and $1.5 \mathrm{~V}$ or $3 \mathrm{~V}$ vs. $\mathrm{Li}^{+} / \mathrm{Li}$ with a potentiostat (Biologic VMP3 multichannel) or a battery tester (Neware BTS $5 \mathrm{~V} / 1$ $\mathrm{mA}$ ) at a controlled temperature of $25^{\circ} \mathrm{C}$. Cyclic voltammetry was also performed in the same voltage range at a scan rate of $0.05 \mathrm{mV} . \mathrm{s}^{-1}$.

The wettability of the electrode surface by the electrolyte was evaluated by capacitance measurements. These latter were performed by using CX electrodes on each side of the coin cell as described elsewhere [36]. The electrolyte used was the same as for the half-cell assembly and the cell voltage ranged from -0.3 to $0.3 \mathrm{~V}$. Cyclic voltammetry was performed at a rate of $20 \mathrm{mV} . \mathrm{s}^{-}$ ${ }^{1}$ or $1 \mathrm{mV} \cdot \mathrm{s}^{-1}$ and the capacitance was calculated by taking the slope of the straight line obtained by plotting the charge as a function of the potential. 


\section{Results and discussion}

\subsection{Modulation of the surface chemistry of CX: influence of treatment on mass change}

Two approaches have been used in this work to modify the surface chemistry of the pristine CX. The first consisted in a treatment in dry phase by the use of an oxidant (air) in order to increase the amount of oxygen functional groups at the surface of the CX samples (CX-Ox1 and CX-Ox3). The second method used was to coat the samples (CX-Dopa and CX-Dopa+PEO) by the use of compounds that covered the initial carbon surface. Table 1 shows the mass gain observed for the CX powders after applying the different treatments.

Table 1: Mass gain of the CX powders after different treatments.

\begin{tabular}{ll}
\hline Samples & Mass gain $(\%)$ \\
\hline CX-Ox1 & 1 \\
CX-Ox3 & 1 \\
\hline CX-Dopa & 6 \\
CX-Dopa+PEO & 17 \\
\hline
\end{tabular}

Samples oxidized in air for $1 \mathrm{~h}$ or $3 \mathrm{~h}$ display only a slight mass increase of $1 \%$, probably resulting from the balance between the mass loss due to the evolution of $\mathrm{CO}$ or $\mathrm{CO}_{2}$ and the mass gain due to new oxygen functional groups generated at the material surface. For modifications in aqueous media, the mass gain might be slightly underestimated because of the probable loss of a small part of the powder during the filtration and washing steps. Nevertheless, the mass increase after drying is significant, 6 and $17 \%$ for CX-Dopa and CX-Dopa+PEO, respectively.

\subsection{Pore texture}

The pore texture of the macro-microporous $\mathrm{CX}$, i.e., based on microporous nodules linked together to form a meso-/macro-porous network, was characterized by both gas adsorption and mercury intrusion porosimetry, in order to get information over the entire range of porosity. Fig. 1a shows the nitrogen adsorption-desorption isotherms measured on all the samples studied herein. Table 2 summarizes the values of BET area, $A_{\mathrm{BET}}$, which corresponds to the adsorption of a monolayer of $\mathrm{N}_{2}$ molecules on the total accessible surface (micropores and mesopores). $V_{\mathrm{DR}, \mathrm{N} 2}$ and $V_{\mathrm{DR}, \mathrm{CO} 2}$ are 
also given in Table 2. The micropore volumes calculated by the Dubinin-Raduskevich (DR) method are only given for comparison purposes with the published data, but it is well known that DR overestimates the microporosity. $V_{\mathrm{DR}, \mathrm{CO} 2}$ gives an assessment of the micropores below $1 \mathrm{~nm}$, while $V_{\mathrm{DR}, \mathrm{N} 2}$ is related to pores below $2 \mathrm{~nm}$. The diffusion of $\mathrm{N}_{2}$ at $-196^{\circ} \mathrm{C}$ being slower than that of $\mathrm{CO}_{2}$ at $0^{\circ} \mathrm{C}$, the very narrow pores are not accessible to $\mathrm{N}_{2}$ in the fixed equilibrium time. In the reference $\mathrm{CX}$ as well as in the oxidized samples, $V_{\mathrm{DR}, \mathrm{CO} 2}$ is very similar to $V_{\mathrm{DR}, \mathrm{N} 2}$, or even slightly higher, which shows that there is a significant fraction of pores of diameter less than $0.7 \mathrm{~nm}$ that could not be accessible to $\mathrm{N}_{2}$ at $-196^{\circ} \mathrm{C}$. For this reason, the application of the 2D-NLDFT-HS method, which simultaneously takes into account the two gases to calculate the pore size distribution (PSD), the specific surface area, $S_{\mathrm{NLDFT}}$, and the micropore volume, $V_{\text {micro, }}$, is particularly useful.

Table 2: Textural parameters derived from $\mathrm{N}_{2}$ and $\mathrm{CO}_{2}$ isotherms presented in Fig. 1, and from mercury intrusion (Fig. SI1).

\begin{tabular}{|c|c|c|c|c|c|c|c|c|}
\hline \multirow[b]{3}{*}{ Sample } & \multicolumn{6}{|c|}{ Gas adsorption } & \multicolumn{2}{|c|}{ Hg intrusion } \\
\hline & \multicolumn{2}{|c|}{$N_{2}$} & \multirow{2}{*}{$\begin{array}{c}\mathrm{CO}_{2} \\
V_{\mathrm{DR}, \mathrm{CO} 2} \\
\left(\mathrm{~cm}^{3} \cdot \mathrm{g}^{-1}\right)\end{array}$} & \multicolumn{3}{|c|}{$\mathrm{N}_{2}+\mathrm{CO}_{2}$} & & \\
\hline & $\begin{array}{c}A_{\mathrm{BET}}{ }^{\mathrm{a}} \\
\left(\mathrm{m}^{2} \cdot \mathrm{g}^{-1}\right)\end{array}$ & $\begin{array}{c}V_{\mathrm{DR}, \mathrm{N2}}{ }^{\mathrm{b}} \\
\left(\mathrm{cm}^{3} \cdot \mathrm{g}^{-1}\right)\end{array}$ & & $\begin{array}{l}S_{\mathrm{NLDFT}} \mathrm{c} \\
\left(\mathrm{m}^{2} \cdot \mathrm{g}^{-1}\right)\end{array}$ & $\begin{array}{c}S_{\text {ext }}{ }^{\mathrm{c}} \\
\left(\mathbf{m}^{2} \cdot \mathbf{g}^{-1}\right)\end{array}$ & $\begin{array}{c}V_{\text {micro }}{ }^{\mathrm{c}} \\
\left(\mathrm{cm}^{3} \cdot \mathrm{g}^{-1}\right)\end{array}$ & $\begin{array}{c}V_{\text {int }}{ }^{\mathrm{d}} \\
\left(\mathrm{cm}^{3} \cdot \mathrm{g}^{-1}\right)\end{array}$ & $\begin{array}{c}d_{\mathbf{p}}{ }^{\mathrm{e}} \\
(\mathbf{n m})\end{array}$ \\
\hline CX-Ref & 723 & 0.27 & 0.25 & 921 & 56 & 0.25 & 1.2 & 82 \\
\hline $\mathrm{CX}-\mathrm{Ox} 1$ & 688 & 0.27 & 0.28 & 945 & 59 & 0.25 & 1.2 & 83 \\
\hline $\mathrm{CX}-\mathrm{Ox} 3$ & 715 & 0.28 & 0.26 & 935 & 58 & 0.26 & 1.2 & 81 \\
\hline CX-Dopa & 195 & 0.08 & 0.17 & 597 & 56 & 0.15 & 1.1 & 82 \\
\hline $\begin{array}{c}\text { CX- } \\
\text { Dopa+PEO }\end{array}$ & 88 & 0.04 & 0.09 & 341 & 46 & 0.08 & 1.0 & 82 \\
\hline
\end{tabular}

${ }^{\mathrm{a}} \mathrm{BET}$ area calculated in the appropriate $\mathrm{P} / \mathrm{P}^{0}$ range with an accuracy of $\pm 5 \%$ [37]

${ }^{\mathrm{b}}$ Micropore volume calculated by the Dubinin-Radushkevich method [38] with an accuracy of \pm 0.01 $\mathrm{cm}^{3} \cdot \mathrm{g}^{-1}$

${ }^{\mathrm{c}}$ Specific surface area calculated by the 2D-NLDFT-HS model [39-40]

${ }^{\mathrm{d}} \mathrm{Hg}$ uptake without inter-particle voids [32]

${ }^{\mathrm{e}}$ Average pore size calculated by the Washburn equation [41] 

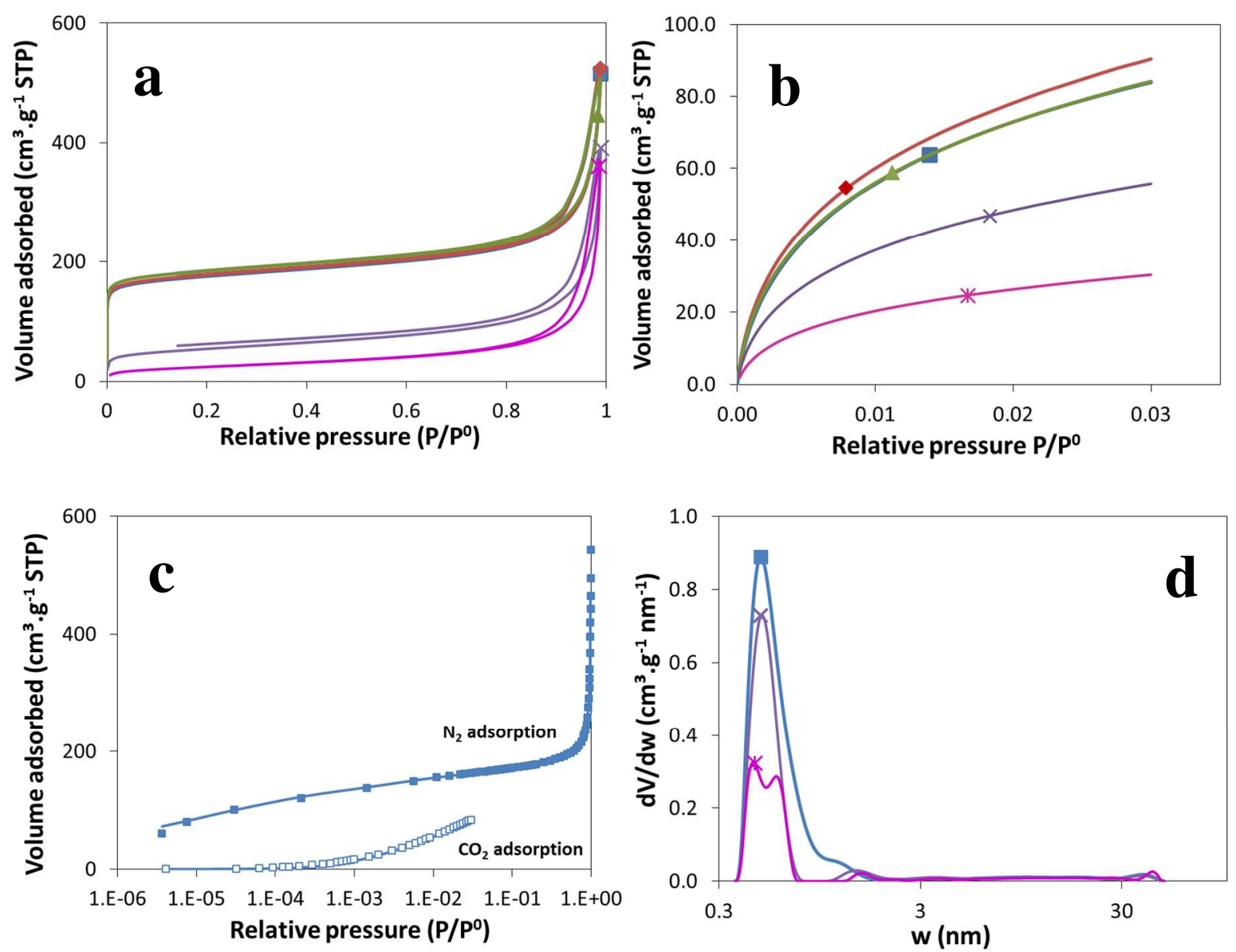

Fig. 1: (a) $\mathrm{N}_{2}$ adsorption-desorption isotherms ( $\square$ ) CX-Ref, $(\diamond) \mathrm{CX}-\mathrm{Ox} 1,(\triangle) \mathrm{CX}-\mathrm{Ox} 3,(\times) \mathrm{CX}-$ Dopa and (*) CX-Dopa+PEO; (b) $\mathrm{CO}_{2}$ adsorption isotherms (same symbols as in (a)); (c) $\mathrm{N}_{2}(\square$ ) and $\mathrm{CO}_{2}(\square)$ adsorption isotherms on CX-Ref fitted simultaneously by SAIEUS ${ }^{\circledR}$; (d) PSD of CXRef, CX-Dopa and CX-Dopa+PEO (same symbols as in (a)).

The $\mathrm{N}_{2}$ adsorption-desorption isotherm of CX-Ref is the combination of two types of isotherms according to the IUPAC classification [42]: type Ia, with a high $\mathrm{N}_{2}$ uptake at low $\mathrm{P} / \mathrm{P}^{0}$ corresponding to a significant volume of narrow micropores, and type II, characteristic of macroporous solids (Fig. 1a). The $\mathrm{N}_{2}$ isotherms of the samples having undergone the oxidation treatment are almost superimposed to that of the reference sample, indicating no change in pore texture. Fig. $1 \mathrm{~b}$ further shows that the $\mathrm{CO}_{2}$ adsorption isotherms of the oxidized and reference samples are perfectly superimposed, confirming that the oxidation treatments did not modify the micropore texture. On the other hand, the adsorbed volume of $\mathrm{N}_{2}$ (Fig. 1a) and $\mathrm{CO}_{2}$ (Fig. 1b) decreases in the case of the coated samples, suggesting a strong reduction of the microporosity of 
the materials. Indeed, the micropore volume decreases from $0.25 \mathrm{~cm}^{3} / \mathrm{g}(\mathrm{CX}-\mathrm{Ref})$ to $0.15 \mathrm{~cm}^{3} / \mathrm{g}$ for CX-Dopa and $0.08 \mathrm{~cm}^{3} / \mathrm{g}$ for CX-Dopa+PEO. Fig. 1c shows the good simultaneous fit of the $\mathrm{N}_{2}$ and $\mathrm{CO}_{2}$ isotherms for CX-Ref: equally good fits were obtained for the isotherms of all materials. Compared to $S_{\mathrm{NLDFT}}$, it is observed that $A_{\mathrm{BET}}$ underestimates the specific area of all the samples due to the inherent limitations of the BET method when applied to microporous solids, but also because $A_{\mathrm{BET}}$ is determined from $\mathrm{N}_{2}$ adsorption and all pores are not accessible to $\mathrm{N}_{2}$ at $196^{\circ} \mathrm{C}$. On the contrary, $A_{\mathrm{BET}}-0 v e r e s t i m a t e s$ the specific area of the coated $\mathrm{CX}$ samples, which are essentially mesoperous. The reasen is that, in wide micropores, $\mathrm{N}_{z}$ tptake proceeds by pore filling and not by monelayer adserption, as assumed by the BET methed. The calculation of the external surface area, $S_{\text {ext }}$, shows that, except for the sample CX-Dopa+PEO, all materials have an external surface area of $57 \pm 2 \mathrm{~m}^{2} \mathrm{~g}^{-1}$. The latter uncertainty is within the inherent error of the gas adsorption technique. CX-Dopa+PEO has an external surface area of $46 \mathrm{~m}^{2} \mathrm{~g}^{-1}$, i.e. $20 \%$ lower than that of CX-Ref. Therefore, neither the oxidation treatments nor the coating with dopamine produced any relevant change in the mesoporosity, CX-Dopa being affected only in its microporous surface area that was reduced from 864 (CX-Ref) to $541 \mathrm{~m}^{2} \mathrm{~g}^{-1}$ (CX-Dopa).

Fig. 1d shows the PSD of CX-Ref, CX-Dopa and CX-Dopa+PEO. CX-Ref shows a considerable amount of pores below $2 \mathrm{~nm}$ with a maximum at $0.47 \mathrm{~nm}$, i.e., in the ultramicropore range. CXDopa shows a PSD with a peak at $1.43 \mathrm{~nm}$, i.e., in the supermicropore range, and a reduction of pores below $0.70 \mathrm{~nm}$, probably being filled or blocked by the polydopamine coating. CXDopa+PEO features a further reduction of pores with sizes lower than $0.7 \mathrm{~nm}$ and wider than 1.0 $\mathrm{nm}$, with a PSD peak at $1.50 \mathrm{~nm}$. The $\mathrm{S}_{\mathrm{NLDFT}}$ of CX-Dopa+PEO was reduced to $341 \mathrm{~m}^{2} \mathrm{~g}^{-1}$. The PSD in the mesopore range, $2-50 \mathrm{~nm}$, was very similar and the lower $S_{\text {ext }}$ observed for CXDopa+PEO, $46 \mathrm{~m}^{2} \mathrm{~g}^{-1}$, when compared to CX-Dopa, $56 \mathrm{~m}^{2} \mathrm{~g}^{-1}$, is mainly attributed to the surface area of narrow mesopores that significantly contribute to the materials surface area.

The intrusion volume, $V_{\mathrm{int}}$, as well as the calculated average pore size, $d_{\mathrm{p}}$, derived from mercury intrusion experiments, are also shown in Table 2. Interestingly, whatever the treatment applied, 
the macropore volumes and sizes remain constant. Indeed, for all materials and despite the changes observed in terms of microporosity, the volume of macropores remains at about $1.0-1.2 \mathrm{~cm}^{3} \cdot \mathrm{g}^{-1}$, and the macropore size distribution is centered on $\sim 80 \mathrm{~nm}$. The detailed interpretation of the $\mathrm{Hg}$ porosity measurements is given in the supplementary information (Figure S1 and Table S1).

Finally, in order to get information on the pore texture of the materials when processed as electrodes, the active-material-binder composites were also characterized by the same techniques. Details on composite recovery and characterization are given in [36]. As expected, and in agreement with our previous results, the use of xanthan gum as a binder does not modify the pore texture of the material after being processed as an electrode. This means that the pore texture of the material in the electrode is really the same as that of the starting CX, regardless the modification treatments that were applied.

\subsection{Particle sizes}

Laser granulometry measurements were performed in order to evaluate the influence of surface modification treatments on the final particle size distributions of the powders. Figure S2 in the supplementary information compares the final particle size distributions of powder particles that have undergone the different treatments. The various post-synthesis treatments do not affect the particle size distribution of the final powders, for each studied material, so that this variable can be discarded when comparing the electrochemical behavior of the CX materials.

\subsection{Surface chemistry}

The surface composition of the reference and modified CX samples and modifications are derived from the XPS analysis on high-resolution O1s (Fig. 2), C1s (Fig. S4), N1s and S2p spectra. Both the air oxidation and the surface coating treatments are expected to affect the oxygen content at the CX surface; for this reason, a particular attention was devoted to the peak fitting of O1s and C1s scans, from which the chemical environments of the grafted oxygen atoms can be derived (Tables 3, 4 and Table S4). Nitrogen, from amine groups, is used to monitor the presence of the polydopamine coating on the $\mathrm{CX}$ surface whereas sulfur, from thiol groups, is used to monitor the 
successful second surface modification in the CX-Dopa+PEO sample.

The results show that each treatment affects the relative content of heteroatoms on the surface of CX powders differently. In particular, the oxygen content in CX-Ref (2.3\%) increases with the duration of air oxidation, reaching $4.9 \%$ after $1 \mathrm{~h}(\mathrm{CX}-\mathrm{Ox} 1)$ and $5.4 \%$ after $3 \mathrm{~h}(\mathrm{CX}-\mathrm{Ox} 3)$ (Table 3). This trend was further confirmed by elemental analysis, showing that the bulk oxygen content increases from 5.6 wt. \% in CX-Ref to 11.5 wt. \% in the CX-Ox3 xerogel.

A closer look at the high-resolution $\mathrm{C} 1 \mathrm{~s}$ and $\mathrm{O} 1 \mathrm{~s}$ spectra allows separating the contributions of oxides $(\mathrm{C}-\mathrm{O}-\mathrm{C})$ and hydroxyls $(\mathrm{H}-\mathrm{O}-\mathrm{C})$ from carbonys $(\mathrm{R}-\mathrm{C}=\mathrm{O})$ and carboxyls $(\mathrm{O}-\mathrm{C}=\mathrm{O})$. In particular, the air oxidation treatment mainly introduces oxide, hydroxyl and carbonyl groups at the CX surface (Fig. 2B and 2C and Table 4). For coated samples, the in situ formation of polydopamine roughly doubles the surface amount of oxygen from 2.3 in CX-Ref to 5.5 at. \%. by mainly introducing hydroxyl (H-O-C) groups. The successful polydopamine coating is confirmed by the presence of about 0.8 at. \% nitrogen on the CX-Dopa sample surface (Table 3). The additional grafting of PEO on the CX-Dopa further increases the oxygen content to $9.8 \%$ by mainly introducing oxide and hydroxyl groups. The nitrogen signal from dopamine is slightly screened by the outermost PEO-SH layer; the presence of sulfur $(0.3 \%)$ from thiol groups confirms the successful grafting of PEO-SH molecules. This suggests that PEO-SH grafting on polydopamine occurs via the formation $\mathrm{C}-\mathrm{O}-\mathrm{C}$ bridges with $\mathrm{OH}$ groups from polydopamine.

To sum up, the surface modifications carried out in this work allow obtaining a series of macroporous carbon xerogels with surface oxygen contents from $2.3 \%$ to $9.8 \%$, and characterized by different types of oxygen functional groups. Moreover, the polydopamine+PEO coating introduces a small fraction of nitrogen and sulfur functional groups $(\sim 1 \%)$ at the CX surface. 

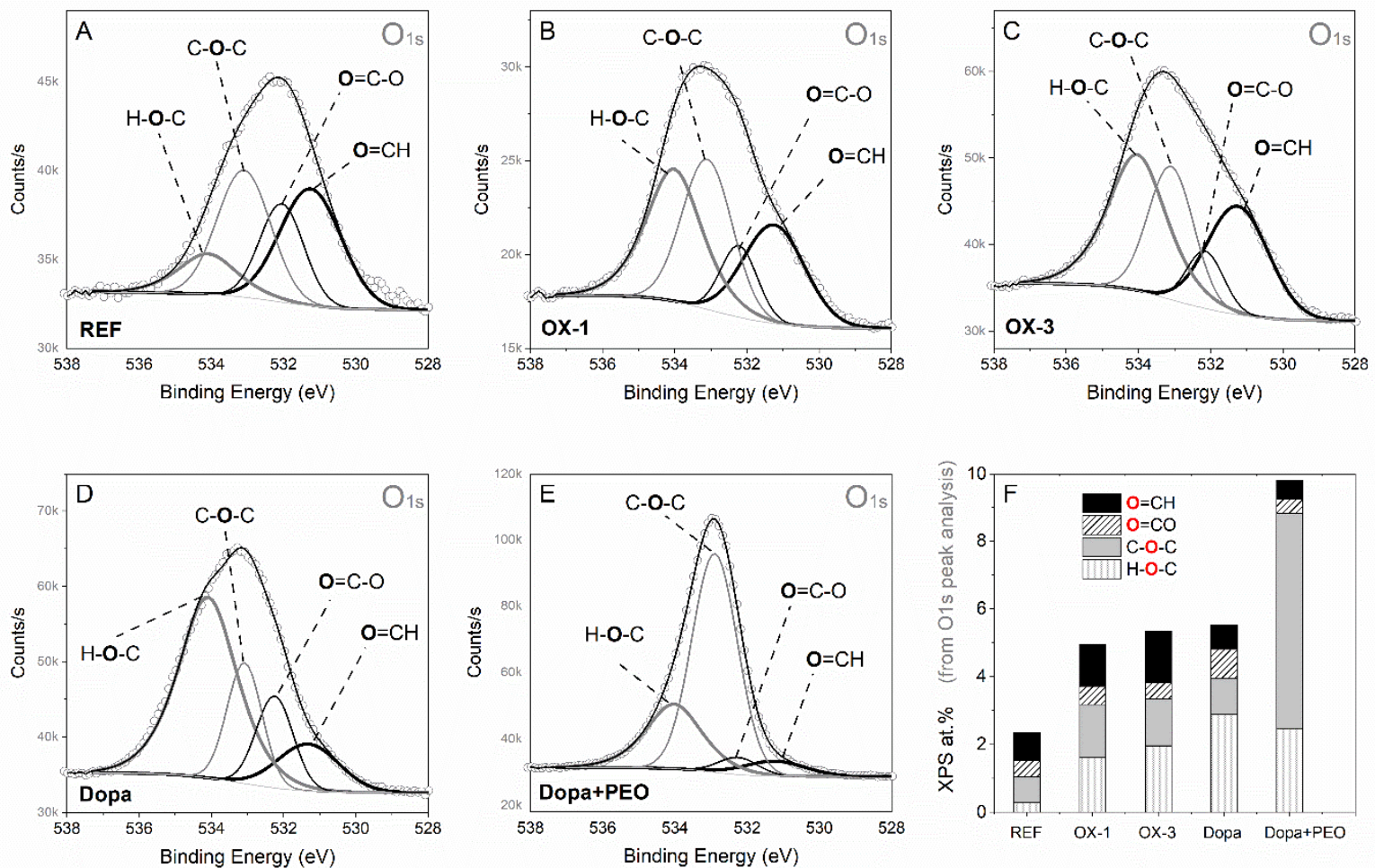

Fig. 2: (A-E) High-resolution O1s photoelectron spectra from the reference and modified CX samples allowing to separate contributions from oxide/hydroxides (C-O-C, H-O-C) and carbonyl/ carboxyl $(\mathrm{O}=\mathrm{CH}, \mathrm{O}=\mathrm{CO})$ functional groups. $(\mathrm{F})$ Bar plot showing the derived quantification (atomic \%).

Table 3: Atomic percentages measured by XPS at the surface of CX-Ref and modified CX powders. Error bars are estimated from background subtraction and peak-fitting accuracies.

\begin{tabular}{lllll}
\hline \multirow{2}{*}{ Sample } & $\mathbf{\%}$ & $\mathbf{\%}$ & $\mathbf{\%}$ & $\mathbf{\%}$ \\
\cline { 2 - 5 } & \pm 0.5 & \pm 0.5 & \pm 0.1 & \pm 0.1 \\
\hline CX-Ref & 97.7 & 2.3 & $/$ & $/$ \\
\hline CX-Ox1 & 94.9 & 4.9 & $/$ & $/$ \\
CX-Ox3 & 94.6 & 5.4 & $/$ & $/$ \\
\hline CX-Dopa & 93.6 & 5.5 & 0.8 & $/$ \\
CX-Dopa+PEO & 89.2 & 9.8 & 0.6 & 0.3 \\
\hline
\end{tabular}


Table 4: Binding energies and quantification (atomic \%) of surface chemical groups derived from XPS surface analysis on reference and modified CX samples. The quantification corresponds to the peak fitting of the O1s spectra shown in Fig. 2.

\begin{tabular}{lllll}
\hline Chemical function & $\mathrm{H}-\mathrm{O}-\mathrm{C}$ & $\mathrm{C}-\mathrm{O}-\mathrm{C}$ & $\mathrm{O}=\mathrm{CO}$ & $\mathrm{O}=\mathrm{CH}$ \\
\cline { 2 - 5 } Binding energy (ev) & 534 & 533 & 532 & 531.5 \\
\hline CX-Ref & 0.3 & 0.7 & 0.5 & 0.8 \\
\hline CX-Ox1 & 1.6 & 1.5 & 0.5 & 1.3 \\
CX-Ox3 & 2.0 & 1.4 & 0.5 & 1.5 \\
\hline CX-Dopa & 2.9 & 1.0 & 0.9 & 0.7 \\
CX-Dopa+PEO & 2.5 & 6.3 & 0.4 & 0.6 \\
\hline
\end{tabular}

\subsection{Electrochemical properties}

3.5.1. Evaluation of the CX surface accessibility by the electrolyte

The assembly, as well as the method used to calculate the capacitance value, are described elsewhere [36]. In such a system, where identical CX electrodes are used on each side of the coin cell with a separator soaked with electrolyte placed in-between, no electrochemical reaction occurs, but only a charge separation that is proportional to the surface accessible by the electrolyte. Fig. 3 compares the cyclic voltammetry curves at a scan rate of $20 \mathrm{mV} . \mathrm{s}^{-1}$ for all the studied samples. In the case of the samples oxidized in air (Fig. 3a), the curves show an increase of the specific current over the entire voltage range and a signal of less rectangular shape accounting for an increase of internal resistance. In the case of coated samples (Fig. 3b), the curves have the same shape as CX-Ref and show values of specific current slightly lower than for CX-Ref. Fig. 3c compares the capacitance values and the increment obtained when the scan rate decreases to 1 $\mathrm{mV} . \mathrm{s}^{-1}$, which is more representative of the exchange kinetics observed during the characterization of a Li-ion half-cell with similar materials.

Oxidation in air increases the specific capacitance value from 4.6 F. $\mathrm{g}^{-1}$ for CX-Ref to $9.0 \mathrm{~F} . \mathrm{g}^{-1}$ for 
CX-Ox3 when cycling is performed at $20 \mathrm{mV} \cdot \mathrm{s}^{-1}$. Moreover, when the scan rate is lowered to 1 $\mathrm{mV} . \mathrm{s}^{-1}$, an even higher specific capacitance value is obtained for CX-Ox3 $\left(14.0 \mathrm{~F} . \mathrm{g}^{-1}\right)$. The longer the activation time, the higher this additional capacitance. Oxidation therefore has the effect of significantly increasing the accessibility of the electrolyte used for the electrochemical characterization to the internal part of the carbon material. Indeed, as shown by the results in Fig. 1 and Table 2, the pore texture remains almost unchanged upon CX oxidation. The increased accessibility to the carbon network can thus only be related to the presence of oxygen groups. The sample modified by surface coating shows capacitance values that are only slightly reduced when compared to CX-Ref, despite the large decrease of microporosity. Two important outcomes follow from this observation:
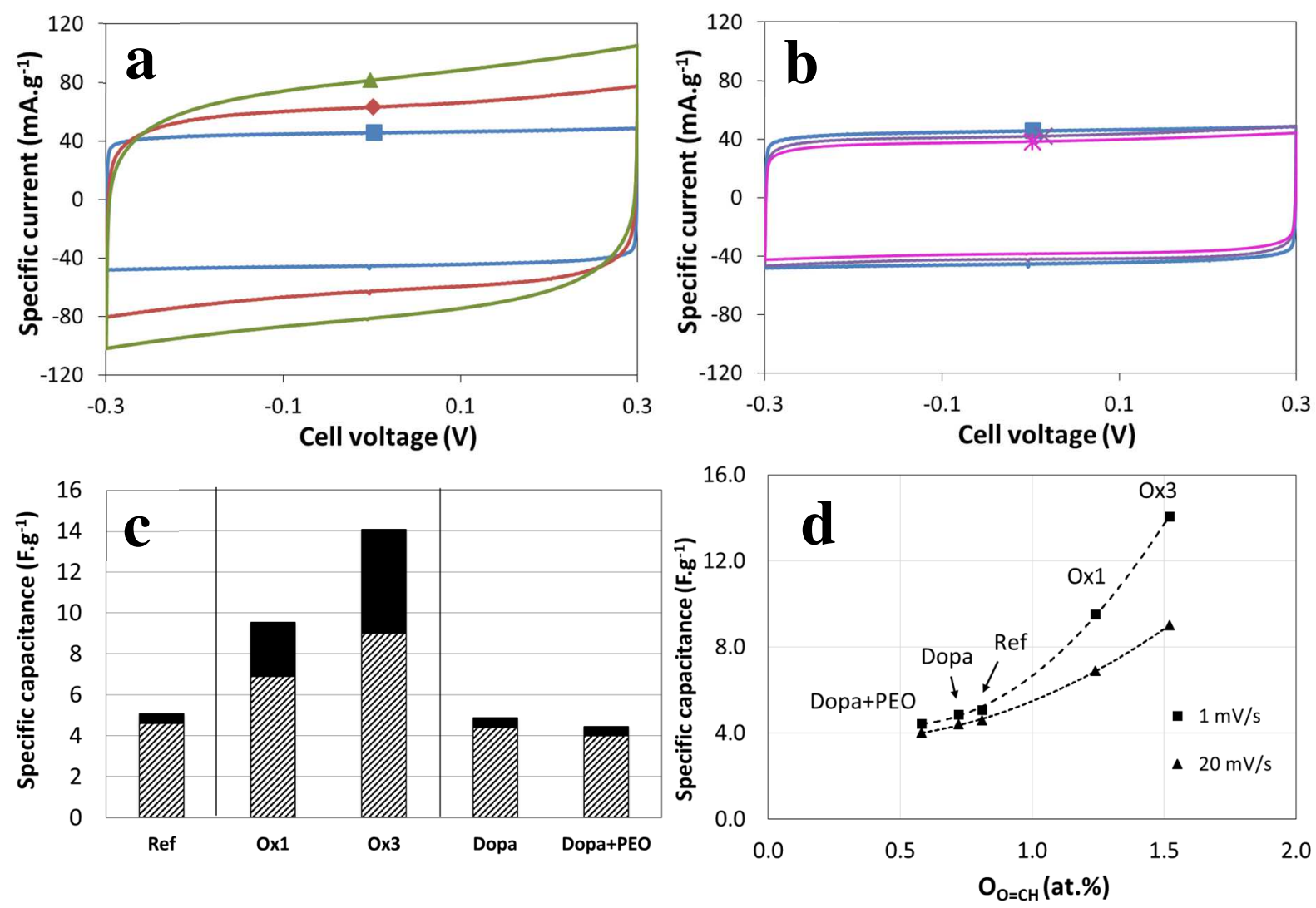

Fig. 3: (a) and (b) Cyclic voltammetry curves obtained at a scan rate of $20 \mathrm{mV} \cdot \mathrm{s}^{-1}$ with the supercapacitor type assembly for $(\square)$ CX-Ref, $(\diamond)$ CX-Ox1, ( $\triangle$ ) CX-Ox3, (×) CX-Dopa and (*) CX-Dopa+PEO; (c) Specific capacitance values for CX-Ref and modified CX samples. The hatched bars correspond to the specific capacitance measured at a scan rate of $20 \mathrm{mV} . \mathrm{s}^{-1}$ and the plain bars stand for the additional capacitance observed when the scan rate is reduced to $1 \mathrm{mV} . \mathrm{s}^{-}$ ; (d) Evolution of the specific capacitance as a function of the surface $\mathrm{O}=\mathrm{CH}$ contents. 
(i) Since the capacitance is nearly the same for the coated samples and CX-Ref, the micropores are not accessible to the electrolyte and consequently should not play a key role in the insertion of $\mathrm{Li}^{+}$, in good agreement with our previous studies $[30,36]$. The $\mathrm{Li}^{+}$storage would in this case be more dictated by the external surface area, although it has been shown that micropores could become accessible after being expanded by some activation process.

(ii) Unlike oxidation, for coating treatments, despite the high oxygen content at the surface as compared to CX-Ref, the presence of oxide (C-O-C) and hydroxide groups $(\mathrm{C}-\mathrm{OH})$ appears to have a low influence on the accessibility of the electrolyte to the CX porosity since the capacitance remains nearly unchanged. The small decrease in capacitance could be ascribed to the slight reduction of the accessible external surface area after the coating treatments.

Given all these data, the differences observed in electrochemical behavior cannot be explained in terms of changes in textural properties but rather in terms of the distribution of types of oxygen moieties. Indeed, the total amounts of oxygen groups are very similar for CX-Ox3 and CX-Dopa (Table 3), but the accessibility, represented by the capacitance, is much lower for the latter material. The main difference lies in the amount of surface $\mathrm{O}=\mathrm{CH}$ species, which is equal to 1.5 and 0.7 at. \% for CX-Ox3 and CX-Dopa, respectively. As seen in Fig. 3d, an upward trend can be evidenced if the capacitance is represented as a function of the atomic percentage of surface $\mathrm{O}=\mathrm{CH}$ groups. The increase is even more pronounced for the slow scanning rate, proving that these moieties favor access of the electrolyte to the carbon structure. This finding is in partial agreement with observations made by Chen et al. claiming that carbonyl $(\mathrm{C}=\mathrm{O})$ and carboxyl $(\mathrm{O}-\mathrm{C}=\mathrm{O})$ groups promote wettability and enhance the electrochemical performance of the materials [43]. 


\subsubsection{Electrochemical behavior in a half-cell assembly}

The galvanostatic charge-discharge curves obtained in a half-cell assembly at a rate of $\mathrm{C} / 10$ for the first cycle for all the studied samples are shown in Fig. 4. The discharge of the half-cell corresponds to the insertion of $\mathrm{Li}^{+}$ions into the carbon structure while the charge corresponds to their de-insertion.
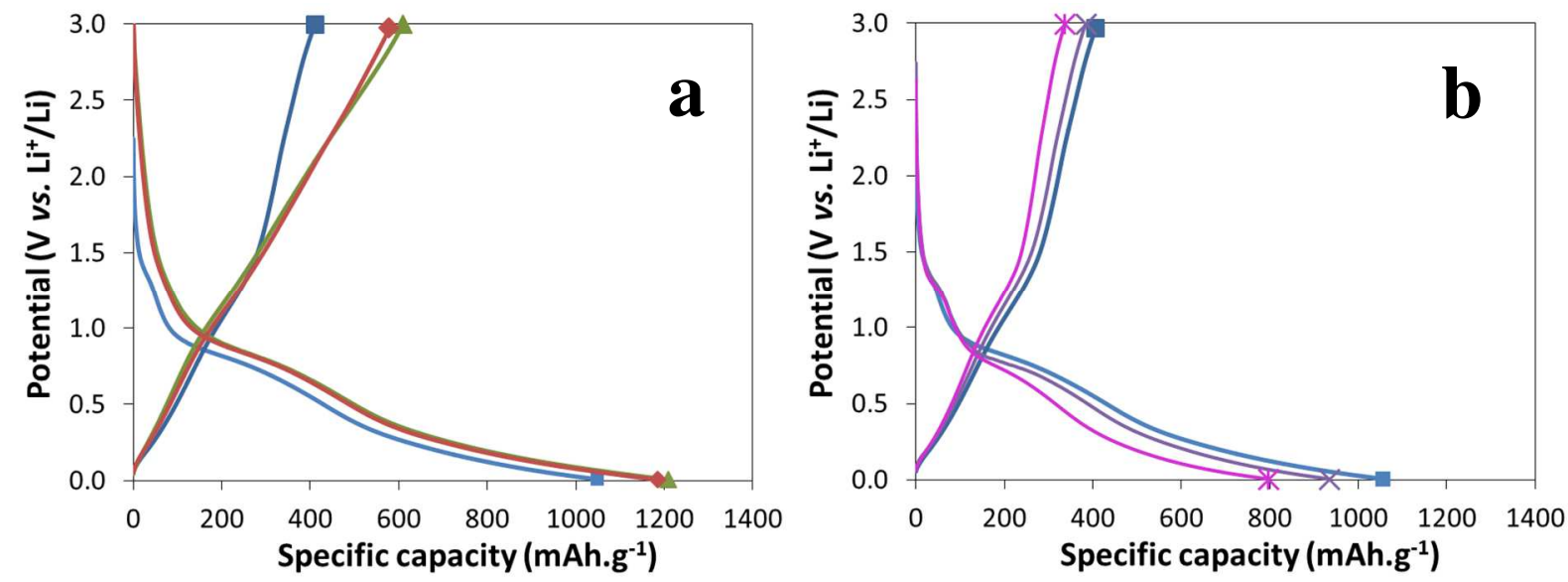

Fig. 4: Galvanostatic charge-discharge curves at the first cycle at a rate of $C / 10$ for: (a) ( $\square$ ) CX-

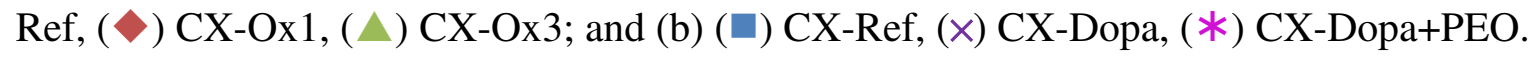

Considering the discharge curves of Fig. 4a and the corresponding numerical values in Table 5, an increase in the $\mathrm{Li}^{+}$insertion capacity can be noticed for the oxidized samples, which is in agreement with the increased electrolyte accessibility evidenced by the capacitance measurements although a higher $\mathrm{Li}^{+}$insertion capacity would have been expected for $\mathrm{CX}-\mathrm{Ox} 3$. The de-insertion will then be discussed for cut-off voltages of 1.5 and $3.0 \mathrm{~V} v s . \mathrm{Li}^{+} / \mathrm{Li}$. Indeed, the working potential of anodes in Li-ion batteries should be kept as low as possible. However, as shown in a previous study, the conclusions on the electrochemical behavior can sometimes be very different depending on which value of final potential is considered [36]. For a cut-off voltage set at $1.5 \mathrm{~V} v s . \mathrm{Li}^{+} / \mathrm{Li}$, oxidation in air causes a slight increase in the charge capacity in the first cycle as compared to the reference CX (Fig. 4a). Above this potential, a strong and continuous increase in the capacity is observed. As the textural properties of the materials are almost unchanged after air oxidation, the substantial increase of carbonyl groups is thus interpreted as the driving mechanism for the high 
additional de-insertion capacity recorded between 1.5 and $3.0 \mathrm{~V} v s . \mathrm{Li}^{+} / \mathrm{Li}$. This is in agreement with what is reported in the literature, where carbonyl groups are claimed to increase the $\mathrm{Li}^{+}$ storage [44-45], but it should be noted that this increase occurs mainly at the highest de-insertion voltages.

Table 5: Numerical values associated with electrochemical measurements performed at a maximum potential of 1.5 and $3.0 \mathrm{~V} v s . \mathrm{Li}^{+} / \mathrm{Li}$ (data corresponding to the first cycle).

\begin{tabular}{|c|c|c|c|c|c|c|}
\hline \multirow{3}{*}{ Sample } & \multirow{3}{*}{$\begin{array}{c}Q_{\text {ins }}^{\mathrm{a}} \\
\left(\mathbf{m A h} \cdot \mathrm{g}^{-1}\right) \\
\pm 5 \%\end{array}$} & \multicolumn{2}{|c|}{$1.5 \mathrm{~V} v s . \mathrm{Li}^{+} / \mathrm{Li}$} & \multicolumn{2}{|c|}{ 3.0 V vs. $\mathrm{Li}^{+} / \mathrm{Li}$} & \multirow[b]{2}{*}{$\begin{array}{c}Q_{\text {rev add. }}{ }^{d} \\
(\%)\end{array}$} \\
\hline & & $\begin{array}{c}Q_{\mathrm{rev}}^{\mathrm{b}} \\
\left(\mathbf{m A h} \cdot \mathrm{g}^{-1}\right)\end{array}$ & $\begin{array}{c}Q_{\mathrm{irr}} / Q_{\mathrm{rev}}{ }^{\mathrm{c}} \\
(-)\end{array}$ & $\underset{\left(\mathbf{m A h} \cdot \mathrm{g}^{-1}\right)}{Q_{\text {rev }}^{\mathrm{b}}}$ & $\begin{array}{c}Q_{\text {irr }} / Q_{\text {rev }}{ }^{\mathrm{c}} \\
(-)\end{array}$ & \\
\hline & & $\pm 5 \%$ & \pm 0.1 & $\pm 5 \%$ & \pm 0.1 & $\pm 5 \%$ \\
\hline CX-Ref & 1032 & 281 & 2.7 & 410 & 1.5 & 46 \\
\hline CX-Ox1 & 1186 & 320 & 2.8 & 587 & 1.0 & 83 \\
\hline $\mathrm{CX}-\mathrm{Ox} 3$ & 1207 & 295 & 3.1 & 610 & 0.9 & 107 \\
\hline CX-Dopa & 940 & 270 & 2.5 & 384 & 1.4 & 42 \\
\hline CX-Dopa+PEO & 789 & 246 & 2.2 & 336 & 1.4 & 37 \\
\hline
\end{tabular}

${ }^{\mathrm{a}}$ Insertion capacity at the first cycle of charge-discharge

${ }^{\mathrm{b}}$ Reversible capacity corresponding to the charge (de-insertion) capacity of the half-cell

${ }^{\mathrm{c}}$ Ratio between the irreversible capacity $\left(Q_{\text {irr }}=Q_{\text {ins1 }}-Q_{\text {rev1 }}\right)$ and the reversible capacity at the first chargedischarge cycle

${ }^{\mathrm{d}}$ Additional reversible capacity between 1.5 and $3.0 \mathrm{~V} v s . \mathrm{Li}^{+} / \mathrm{Li}(\%)$

A more accurate insight into the first cycle behavior can be obtained by considering the $Q_{\text {irr }} / Q_{\text {rev }}$ ratio. This dimensionless value, independent of the mass of active material, represents the relative irreversible losses occurring at the first cycle and should be as low as possible. If the cut-off potential is set at $1.5 \mathrm{~V} v s$. $\mathrm{Li}^{+} / \mathrm{Li}$, the ratio is increased compared to CX-Ref (Table 5). Since the pore texture remains unaltered, these results indicate that a higher quantity of $\mathrm{Li}^{+}$ions is introduced into the carbon network during the first discharge, due to the better electrolyte accessibility provided by the presence of carbonyl groups. However, since the de-insertion remains in the same range as for the reference material, these additional ions cannot be retrieved at $1.5 \mathrm{~V} v s$. $\mathrm{Li}^{+} / \mathrm{Li}$. A substantially higher de-insertion capacity is recorded for the oxidized materials if the voltage is raised to $3.0 \mathrm{~V} v s$. $\mathrm{Li}^{+} / \mathrm{Li}$ (Fig. $4 \mathrm{a}$ and Table 5). As a result, the $Q_{\text {irr }} / Q_{\text {rev }}$ ratio decreases from 1.5 to $\sim 1.0$, showing that relatively fewer $\mathrm{Li}^{+}$ions remain irreversibly trapped within the carbon network. As such, the oxidation treatment in air allows storing more lithium ions that, however, 
interact more strongly with the material, thus requiring a higher potential to be retrieved. It should be recalled that such a conclusion can be drawn here from the fact that the processing into electrodes by using xanthan gum, used as binder, does not modify the pore texture of the starting material. This could very well not be the case for composite electrodes processed using PVDF, which is known to alter the starting porosity.

In the case of coated samples, the insertion capacity at the first cycle decreases compared to the uncoated CX (Fig. 4b and Table 5). As deduced from the capacitance measurements, the lower $\mathrm{Li}^{+}$accommodation could possibly be related to a reduction in the external surface area accessible due to the coating. The same observations are made for the first-cycle de-insertion, regardless of the cut-off voltage considered. From these data as well as those from capacitance measurements, it appears that the oxygen functionalities brought by the coatings do not influence the accessibility to the electrolyte and therefore the $\mathrm{Li}^{+}$insertion and de-insertion capacities. Despite the higher overall oxygen contents and the strong increase in surface oxide and hydroxyl groups, the capacities tend to decrease and the shape of the de-insertion (charge) curves for the coated materials is very similar to that of the CX-Ref material. Such behavior is opposite from observations made by Kuo et al. suggesting that phenolic groups strongly participate to capacity at voltages above $1.5 \mathrm{~V} v s . \mathrm{Li}^{+} / \mathrm{Li}[46]$.

Interestingly, if the cut-off voltage is set at $1.5 \mathrm{~V} v s . \mathrm{Li}^{+} / \mathrm{Li}$, the $Q_{\text {irr }} / Q_{\text {rev }}$ ratio decreases, indicating that there are less relative irreversible losses for the coated materials. As such, the coatings lead to better-performing materials, possibly by masking some surface functionalities of CX-Ref where $\mathrm{Li}^{+}$ions are trapped more strongly or irreversibly. If cycling is performed up to $3.0 \mathrm{~V} v s . \mathrm{Li}^{+} / \mathrm{Li}$, the $Q_{\text {irr }} / Q_{\text {rev }}$ ratio for the coated samples remains in the same range as the reference carbon. These results confirm that relatively more ions are de-inserted from strongly interacting sites of CX-ref at higher potential, leading to a decrease in the irreversible losses.

All these observations thus suggest that the coating modifies only the accessible external surface area and masks the strongly interacting sites of the carbon xerogel particles rather than providing 
additional sites for the accommodation of $\mathrm{Li}^{+}$ions.
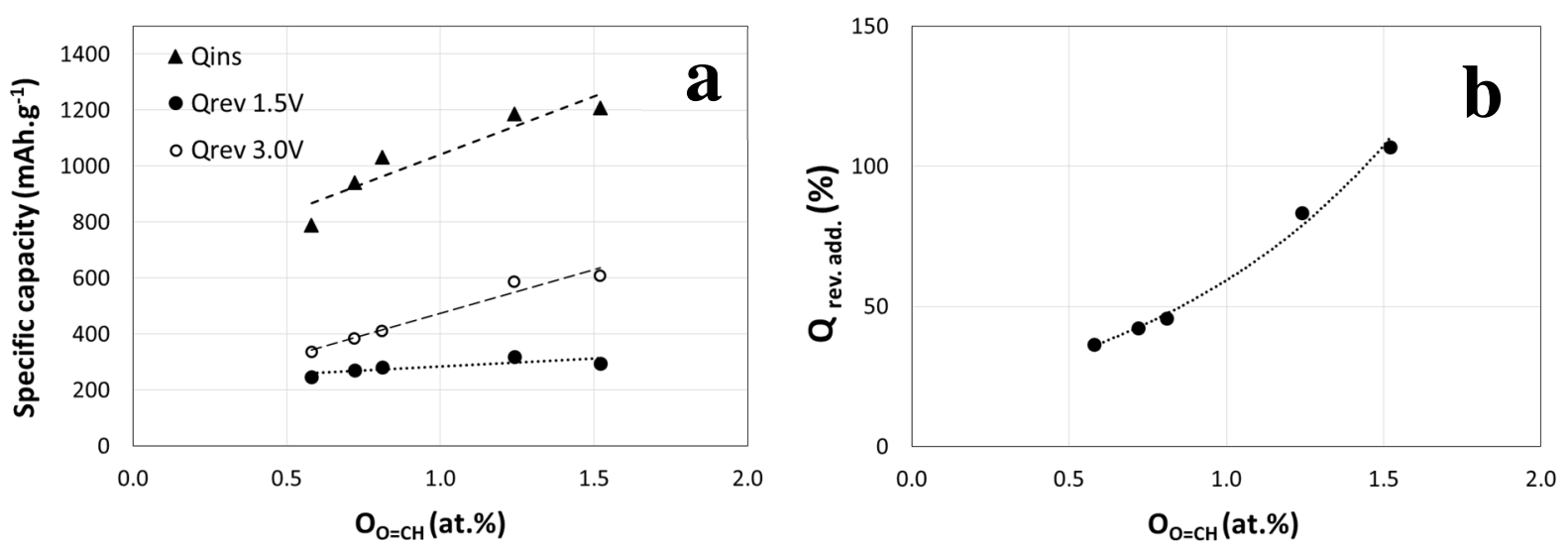

Fig. 5: (a) First-cycle specific insertion capacity $(\boldsymbol{\Delta})$, de-insertion at a cut-off voltage of $1.5 \mathrm{~V} v s$. $\mathrm{Li}^{+} / \mathrm{Li}(\mathbf{O})$ and de-insertion at a cut-off voltage of $3.0 \mathrm{~V} v s . \mathrm{Li}^{+} / \mathrm{Li}(\mathrm{O})$ as a function of the surface $\mathrm{O}=\mathrm{CH}$ contents ; (b) Additional de-insertion capacity (expressed in \%) between 1.5 and $3.0 \mathrm{~V} v$ s. $\mathrm{Li}^{+} / \mathrm{Li}$ as a function of the surface $\mathrm{O}=\mathrm{CH}$ contents.

Similarly to the capacitance measurements, the first-cycle insertion capacity does not depend on the pore texture or to the overall oxygen content, but follows an increasing tendency with the surface $\mathrm{O}=\mathrm{CH}$ contents, resulting from the improved electrolyte accessibility to the carbon network, thus accounting for an enhanced $\mathrm{Li}^{+}$ions accommodation capacity (Fig. 5a). The deinsertion follows this same increasing trend, irrespectively of the cut-off voltage. However, the slope is steeper if the de-insertion potential is set at $3.0 \mathrm{~V} v s . \mathrm{Li}^{+} / \mathrm{Li}$, suggesting that surface $\mathrm{O}=\mathrm{CH}$ groups lead to a stronger trapping of $\mathrm{Li}^{+}$ions within the structure, needing a higher voltage for them to be retrieved. Interestingly, the percentage of additional de-insertion capacity recorded between 1.5 and $3.0 \mathrm{~V}$ vs. $\mathrm{Li}^{+} / \mathrm{Li}$, follows an exponential increase when plotted as a function of the surface $\mathrm{O}=\mathrm{CH}$ groups (Table 5 and Fig. $5 b$ ). In short, higher contents of surface $\mathrm{O}=\mathrm{CH}$ functions render the material accessible to a larger quantity of $\mathrm{Li}^{+}$ions ( $Q_{\text {ins }}$ increases), which however become more difficult to extract (higher voltage needed) due to stronger interactions with the host structure. The combined observations of capacitance measurements and galvanostatic cycling thus indicate that carbonyl groups dictate the accessibility and the storage capacity of $\mathrm{Li}^{+}$ ions.

Finally, the cycling behavior of the materials is compared in Fig. 6. If the cut-off voltage is set at 
1.5 V vs. $\mathrm{Li}^{+} / \mathrm{Li}$ (Fig. 6a), all the samples behave the same, ultimately leading to a stable reversible de-insertion capacity of $200 \mathrm{mAh} . \mathrm{g}^{-1}$. Raising the charge potential up to $3.0 \mathrm{~V} v s . \mathrm{Li}^{+} / \mathrm{Li}^{\text {induces }}$ a different behavior (Fig. 6b). Namely, the air-oxidized samples retain higher values of deinsertion capacities as expected from the observations of the first cycles, but with a decreasing trend when the number of cycles increases. Fig. $6 c$ compares the evolution of the de-insertion capacity for the $1^{\text {st }}$ and the $20^{\text {th }}$ cycle for both cut-off voltages as a function of the surface $\mathrm{O}=\mathrm{CH}$ contents. At $1.5 \mathrm{~V} v s$. $\mathrm{Li}^{+} / \mathrm{Li}$, this parameter does not influence the capacity after 20 cycles anymore, while even higher capacities are recorded for the $\mathrm{O}=\mathrm{CH}$-rich samples at $3.0 \mathrm{~V} v s . \mathrm{Li}^{+} / \mathrm{Li}$. Fig. $6 \mathrm{~d}$ shows the evolution of the ratio of the specific capacity at the $20^{\text {th }}$ cycle to that determined at the $1^{\text {st }}$ cycle. This ratio is independent of the voltage and inversely proportional to the surface $\mathrm{O}=\mathrm{CH}$ content. Consequently, the retention of the specific capacity decreases with cycling in presence of more surface $\mathrm{O}=\mathrm{CH}$ groups. Therefore, if a higher cycling stability or improved capacity retention is desired, then fewer surface carbonyl groups should be achieved. Overall, the oxidation thus allows increasing the $\mathrm{Li}^{+}$ions storage capacity, but this quantity decreases over cycling either due to continuous and progressive irreversible trapping due to the stronger $\mathrm{Li}^{+}-\mathrm{CX}^{-}$ interaction, or due to ageing of the carbon network. The coated samples exhibit very stable cycling, identical to the reference $\mathrm{CX}$, again suggesting that the coatings provide no benefit in terms of electrolyte accessibility or $\mathrm{Li}^{+}$insertion sites. 

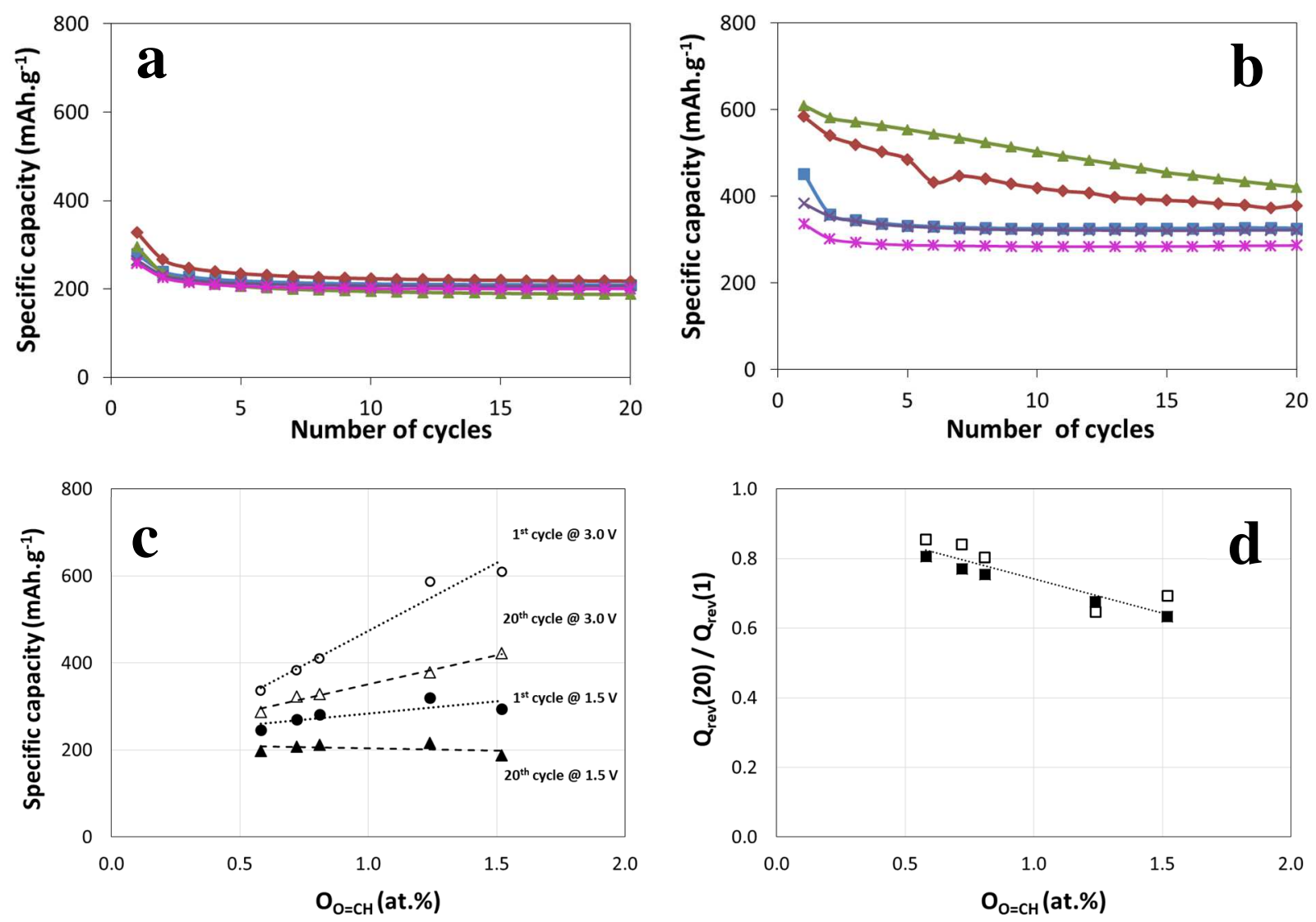

Fig. 6: Cycling behavior at a rate of $\mathrm{C} / 10$ and with a cut-off voltage of: (a) $1.5 \mathrm{~V}$ (a) and (b) 3.0

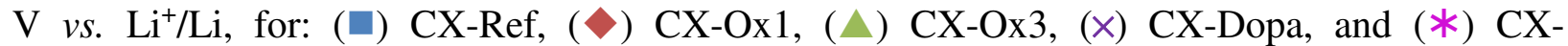
Dopa+PEO; (c) Specific capacities at 1.5 (full symbols) and $3.0 \mathrm{~V}$ (empty symbols) vs. $\mathrm{Li}^{+} / \mathrm{Li}$ at the $1^{\text {st }}($ and $O)$ and $20^{\text {th }}$ cycle $(\boldsymbol{\Delta}$ and $\Delta)$; (d) Ratio of specific capacities at $20^{\text {th }}$ to the $1^{\text {st }}$ cycle (at $1.5(\mathbf{\square})$ and $3.0 \mathrm{~V}(\square) v s$. $\mathrm{Li}^{+} / \mathrm{Li}$ ), as a function of the surface $\mathrm{O}=\mathrm{CH}$ contents.

To summarize the results of electrochemical properties, it appears that coatings introducing hydroxide and oxide species do not allow improving the wettability or accessibility of the electrolyte, but rather mask some sites that could induce irreversible $\mathrm{Li}^{+}$trapping. The presence of the coating also accounts for a small reduction of the external surface area of the material, and therefore a lower overall performance in terms of charge/discharge capacities. On the contrary, an oxidation treatment in air allows hosting a larger quantity of $\mathrm{Li}^{+}$ions that can however only be extracted if a higher voltage is applied. Indeed, in this case, the pore texture is not altered by the treatment, proving that only surface modification, and more exactly the increase of the surface carbonyl species, can explain the improved wettability and accessibility of the electrolyte (and 
hence of $\mathrm{Li}^{+}$ions) to the carbon network. Increasing the contents of these species nevertheless also leads to stronger interactions between the $\mathrm{CX}$ and the $\mathrm{Li}^{+}$ions and, therefore, a higher voltage is needed to extract them. Additional high-voltage de-insertion is not realistic for applications of such materials as anodes for real Li-ion batteries, where the insertion/de-insertion potential should be kept as low as possible. This also highlights the need to carefully consider the end-voltage before drawing any conclusion regarding the performance of the materials and comparing the data with the literature.

The results reported here further confirm the limited role of micropores in carbon xerogels for the lithium storage, which remains dictated by the accessible external surface area. Introducing oxygen functionalities, especially carbonyl groups, enhances the storage capacity at constant pore texture. $\mathrm{Li}^{+}$ions are possibly adsorbed on these sites with strong interactions, rendering their extraction only possible if higher voltages are applied. Further studies would be interesting to shed some light on the exact nature of these interactions in order to better understand the lithium ions storage mechanisms in presence of these surface groups.

\section{Conclusion}

The surface chemistry of a hierarchically porous carbon xerogel (CX) was successfully modified via different techniques: oxidation in air, coating with a polydopamine layer and coating with polydopamine followed by PEO-SH grafting. The different treatments did affect neither the macropore fraction nor the particle size. The micropore fraction was not altered by oxidation in air but the coatings led to a substantial reduction in the micropore volume. The modulation of the surface chemistry was efficient and resulted in a series of samples with different kinds of oxygen functional groups on their surface, as evidenced by XPS analysis, and a similar external surface area. This allowed elucidating the role of surface chemistry of porous carbons on their electrochemical behavior when used as anodes for Li-ion batteries. 
A combination of capacitance and galvanostatic cycling measurements provided a better understanding of the behavior of the modified samples. The coatings did not seem to improve the wettability and accessibility of the electrolyte despite the introduction of oxide and hydroxyl functional groups. On the contrary, the oxidation in air increased the $\mathrm{Li}^{+}$storage capacity by a better accessibility of the electrolyte to the carbon network, which was not caused by any textural change. Overall, the introduction of carbonyl functional groups seemed to increase the electrolyte accessibility and $\mathrm{Li}^{+}$ions storage, but also induced stronger interactions. In this way, higher discharge capacities are only reached for higher voltages, which is not realistic for applications in real Li-ion batteries. To sum up, and contrary to what has been reported in the open literature so far, the results presented here have shown that it is not the total amount of oxygen groups but rather the surface content of carbonyl functions that increase the $\mathrm{Li}^{+}$storage capacity. At the same time, the surface functionalization with carbonyl groups also leads to stronger $\mathrm{Li}^{+} /$electrode interactions. For this reason, at high carbonyl content, the retention of the specific capacity decreases with cycling. Therefore, if better cycling stability is searched, the carbonyl functionalization should be kept low, or a trade-off should be found to ensure higher capacities and cycling stability.

\section{Supporting information:}

Mercury intrusion porosimetry, Laser granulometry, Point of zero charge analysis (PZC), Highresolution $\mathrm{C} 1 \mathrm{~s}$ photoelectron spectra.

\section{Credit authorship contribution statement}

Marie-Laure C. Piedboeuf: Conceptualization, Methodology, Validation, Investigation, Data curation, Writing-Original Draft, Writing- review \& editing, Visualization ; Nathalie Job: Conceptualization, Methodology, Data curation, Supervision, Project administration, Writing review \& editing ; Abdelhafid Aqil: Conceptualization, Methodology, Validation, Investigation, Data curation, Writing- review \& editing ; Yan Busby: XPS measurements, Data curation, Writing- review \& editing ; Vanessa Fierro: $\mathrm{CO}_{2}$ adsorption measurements, Elemental Analysis, Data curation, Writing- review \& editing ; Alain Celzard: Data curation, Writing- review \& editing ; Christophe Detrembleur: Data curation, Supervision, Writing - review \& editing ; 
Alexandre F. Léonard: Conceptualization, Methodology, Validation, Investigation, Data curation, Writing-Original Draft, Writing- review \& editing, Visualization.

\section{Declaration of competing interest}

The authors declare that they have no known competing financial interests or personal relationships that could have appeared to influence the work reported in this paper.

\section{Acknowledgements}

M.-L. Piedboeuf thanks the F.R.S.-FNRS for a FRIA fellowship grant. N. Job and A. Léonard thank the financial support from the Région Wallonne (BATWAL, grant agreement 1318146, PE Plan Marshall 2.vert). V. Fierro, A. Celzard, N. Job and A. Léonard thank the funding from the RFCS (PROMOTEE, grant agreement 709741). The authors also thank the University of Liège (Fonds Spéciaux pour la Recherche FSR C13/09) and the Fonds de Bay for their financial support. Y. Busby acknowledges the support from the Synthesis, Irradiation and Analysis of Materials (SIAM), technological platform of University of Namur. The help of Mr. Philippe Gadonneix for elemental analysis is also greatly acknowledged.

\section{References}

[1] Tarascon, J.M.; Armand, M. Issues and Challenges facing Rechargeable Lithium Batteries. Nature 2001, 414, 359-367. doi:10.1038/35104644.

[2] Aurbach, D.; Zaban, A.; Ein-Eli, Y.; Weissman, I.; Chusid, O.; Markovsky, B.; Levi, M.; Levi, E.; Schechter, A.; Granot, E. Recent Studies on the Correlation Between Surface Chemistry, Morphology, Three-Dimensional Structures and Performance of Li and Li-C Intercalation Anodes in Several Important Electrolyte Systems. J. Power Sources 1997, 68, 91-98. doi:10.1016/S0378-7753(97)02575-5.

[3] Collins, J.; Gourdin, G.; Foster, M.; Qu, D. Carbon Surface Functionalities and SEI Formation During Li Intercalation. Carbon 2015, 92, 193-244. doi:10.1016/j.carbon.2015.04.007.

[4] Fujimoto, H.; Tokumitsu, K.; Mabuchi, A.; Chinnasamy, N.; Kasuh, T. The Anode Performance of the Hard Carbon for the Lithium Ion Battery Derived from the OxygenContaining Aromatic Precursors. J. Power Sources 2010, 195, 452-7456. doi:10.1016/j.jpowsour.2010.05.041.

[5] Ni, J.; Huang, Y.; Gao, L. A High-Performance Hard Carbon for Li-Ion Batteries and Supercapacitors Application. J. Power Sources 2013, 223, 306-311. doi:10.1016/j.jpowsour.2012.09.047.

[6] Aurbach, D.; Markovsky, B.; Weissman, I.; Levi, E.; Ein-Eli, Y. On the Correlation Between Surface Chemistry and Performance of Graphite Negative Electrodes for Li Ion Batteries. Electrochim. Acta 1999, 45, 67-86. doi:10.1016/S0013-4686(99)00194-2.

[7] Tran, C.; Kafle, J.; Yang, X.Q.; Qu, D. Increased Discharge Capacity of a Li-Air Activated Carbon Cathode Produced by Preventing Carbon Surface Passivation. Carbon 2011, 49, 1266-1271. doi:10.1016/j.carbon.2010.11.045.

[8] Mao, Y.; Duan, H.; Xu, B.; Zhang, L.; Hu, Y.; Zhao, C.; Wang, Z.; Chen, L.; Yang, Y. 
Lithium Storage in Nitrogen-Rich Mesoporous Carbon Materials. Energy Environ. Sci. 2012, 5, 57950-7955. doi:10.1039/C2EE21817H.

[9] Anjos, D.M.; McDonough, J.K.; Perre, E.; Brown, G.M.; Overbury, S.H.; Gogotsi, Y.; Presser, V. Pseudocapacitance and Performance Stability of Quinone-Coated Carbon Onions. Nano Energy 2013, 2, 702-712. doi:10.1016/j.nanoen.2013.08.003

[10] Wang, H.G.; Wang, Y.; Li, Y.; Wan, Y.; Duan, Q. Exceptional Electrochemical Performance of Nitrogen-Doped Porous Carbon for Lithium Storage. Carbon 2015, 82, 116-123. doi:10.1016/j.carbon.2014.10.041.

[11] Ventosa, E.; Xia, W.; Klink, S.; La Mantia, F.; Muhler, M.; Schuhmann, W. Influence of Surface Functional Groups on Lithium Ion Intercalation of Carbon Cloth. Electrochim. Acta 2012, 65, 22-29. doi:10.1016/j.electacta.2011.12.128.

[12] Klink, S.; Ventosa, E.; Xia, W.; La Mantia, F.; Muhler, M.; Schuhmann, W. Tailoring of CNT Surface Oxygen Groups by Gas-Phase Oxidation and its Implications for Lithium Ion Batteries. Electrochem. Commun. 2012, 15, 10-13. doi:10.1016/j.elecom.2011.11.012.

[13] Mangun, C.L.; Benak, K.R.; Daley, M.A.; Economy, J. Oxidation of Activated Carbon Fibers: Effect on Pore Size, Surface Chemistry and Adsorption Properties. Chem. Mater. 1999, 11, 3476-3483. doi:10.1021/cm990123m.

[14] Lopez-Ramon, M.V.; Stoeckli, F.; Moreno-Castilla, C.; Carrasco-Marin, F. On the Characterization of Acidic and Basic Surface Sites on Carbons by Various Techniques, Carbon 1999, 37, 1215-1221. doi:10.1016/S0008-6223(98)00317-0.

[15] Jaramillo, J.; Alvarez, P.M.; Gomez-Serrano, V. Oxidation of Activated Carbon by Dry and Wet Methods Surface Chemistry and Textural Modifications. Fuel Process. Technol. 2010, 91, 1768-1775. doi:10.1016/j.fuproc.2010.07.018.

[16] da Silva Pires, M.; Haye, E.; Zubiaur, A.; Job, N.; Pireaux, J.-J.; Houssiau, L.; Busby, Y. Defective Pt-Ni/Graphene Nanomaterials by Simultaneous or Sequential Treatments of Organometallic Precursors by Low-Pressure Oxygen Plasma. Plasma Process Polym. 2019, 16, 1800203. doi: 10.1002/ppap.201800203.

[17] Haye, E.; Busby, Y.; da Silva Pires, M.; Bocchese, F.; Job, N.; Houssiau, L.; Pireaux, J.-J. Low-Pressure Plasma Synthesis of Ni/C Nanocatalysts from Solid Precursors: Influence of the Plasma Chemistry on the Morphology and Chemical State. ACS Appl. Nano Mater. 2018, 1, 265-273. doi:10.1021/acsanm.7b00125.

[18] Mager, N.; Meyer, N.; Léonard, A.F.; Job, N.; Devillers, M.; Hermans, S. Functionalization of Carbon Xerogels for the Preparation of Palladium Supported Catalysts Applied in Sugar Transformations. Appl. Catal. B Environ. 2014, 148-149, 424-435. doi:10.1016/j.apcatb.2013.11.028.

[19] Boehm, H.P. Surface Oxides on Carbon and Their Analysis: A Critical Assessment, Carbon 2002, 40, 145-149. doi:10.1016/S0008-6223(01)00165-8.

[20] Fraga, M.A.; Jordao, E.; Mendez, M.J.; Freitas, M.M.A.; Faria, J.L.; Figueiredo, J.L. Properties of Carbon-Supported Platinum Catalysts: Role of Carbon Surface Sites. J. Catal. 2002, 209, 355-364. doi: 10.1006/jcat.2002.3637.

[21] Gheorghiu, C.C.; Pérez-Cadenas, M.; Román-Martínez, M.C.; Salinas-Martínez de Lecea, C.; Job, N. Immobilization of Homogeneous Catalysts in Nanostructured Carbon Xerogel. Stud. Surf. Sci. Catal. 2010, 175, 647-651. doi:10.1016/S0167-2991(10)75128-4.

[22] Samant, P.V.; Gonçalves, F.; Freitas, M.M.A.; Pereira, M.F.R.; Figueiredo, J.L. Surface Activation of a Polymer Based Carbon. Carbon 2004, 42, 1321-1325.doi: 10.1016/j.carbon.2004.01.034.

[23] Lee, H.; Dellatore, S.M.; Miller, W.M.; Messersmith, P.B. Mussel-Inspired Surface Chemistry for Multifunctional Coatings. Science 2007, 318, 426-430. doi:10.1126/science.1147241.

[24] Zhao, F.Y.; Ji, Y.L.; Weng, X.D.; Mi, Y.F.; Ye, C.C.; An, Q.F.; Goa, C.J., High-Flux Positively Charged Nanocomposite Nanofiltration Membranes Filled with 
Poly(dopamine) Modified Multiwall Carbon Nanotubes. Appl. Mater. Interfaces. 2016, 8 , 6693-6700. doi:10.1021/acsami.6b00394

[25] Park, S.H.; Kim, H.J.; Lee, J.; Jeong, Y.K.; Choi, J.W.; Lee, H. Mussel-Inspired Polydopamine Coating for Enhanced Thermal Stability and Rate Performance of Graphite Anodes in Li-Ion Batteries. ACS Appl. Mater. Interfaces 2016, 8, 13973-13981. doi: 10.1021/acsami.6b04109.

[26] Aqil, A.; Serwas, H.; Delplancke, J.L.; Jérôme, R.; Jérôme, C.; Canet, L. Preparation of Stable Suspensions of Gold Nanoparticles in Water by Sonoelectrochemistry. Ultrason. Sonochem. 2008, 15, 1055-1061. doi:10.1016/j.ultsonch.2008.04.004.

[27] Assegie, A.A.; Cheng, J.H.; Kuo, L.M.; Su, W.N.; Hwang, B.J. Polyethylene Oxide Film Coating Enhances Lithium Cycling Efficiency of an Anode-Free Lithium-Metal Battery. Nanoscale 2018, 10, 6125-6138. doi: 10.1039/c7nr09058g.

[28] Piedboeuf, M.-L.C.; Léonard, A.F.; Deschamps, F.L.; Job, N. Carbon Xerogels as Model Materials: Toward a Relationship Between Pore Texture and Electrochemical Behavior as Anodes for Lithium-Ion Batteries. J. Mater. Sci. 2016, 51, 4358-4370. doi:10.1007/s10853016-9748-3.

[29] Léonard, A. F.; Job, N. Safe and Green Li-Ion Batteries Based on $\mathrm{LiFePO}_{4}$ and $\mathrm{Li}_{4} \mathrm{Ti}_{5} \mathrm{O}_{12}$ Sprayed as Aqueous Slurries with Xanthan Gum as Common Binder. Mater. Today Energy. 2019, 12, 168-178._doi:10.1016/j.mtener.2019.01.008.

[30] Rey-Raap, N.; Piedboeuf, M.-L.C.; Arenillas, A.; Menéndez, J.A.; Léonard, A.F.; Job, N. Aqueous and Organic Inks of Carbon Xerogels as Models for Studying the Role of Porosity in Lithium-Ion Battery Electrodes. Mater. Des. 2016, 109, 282-288. doi:10.1016/j.matdes.2016.07.007.

[31] Job, N.; Pirard, R.; Marien, J.; Pirard J.-P. Porous Carbon Xerogels with Texture Tailored by $\mathrm{pH}$ Control during Sol-Gel Process. Carbon 2004, 42, 619-628. doi:10.1016/j.carbon.2003.12.072.

[32] Piedboeuf, M.-L.C.; Léonard, A.F.; Traina, K.; Job, N. Influence of the Textural Parameters of Resorcinol-Formaldehyde Dry Polymers and Carbon Xerogels on Particle Sizes upon Mechanical Milling. Colloids Surfaces A Physicochem. Eng. Asp. 2015, 471, 124-132. doi:10.1016/j.colsurfa.2015.02.014.

[33] Yu, B.; Wang, X.; Qian, X.; Xing, W.; Yang, H.; Ma, L.; Lin, Y.; Jiang, S.; Song, L.; Hu, Y.; Lo, S. Functionalized Graphene Oxide/Phosphoramide Oligomer Hybrids Flame Retardant Prepared via in situ Polymerization for Improving the Fire Safety of Polypropylene. $R S C$ Adv. 2014, 4, 31782-31794. doi:10.1039/c3ra45945d.

[34] Liu, T.; Kim, K.C.; Lee, B.; Chen, Z.; Noda, S.; Jang, S.S.; Lee, S.W. Self-Polymerized Dopamine as an Organic Cathode for Li- and Na-Ion Batteries. Energy Environ. Sci. 2017, 10, 205-215. doi: 10.1039/c6ee02641a.

[35] Ruiz-Taylor, L.A.; Martin, T.L.; Zaugg, F.G.; Witte, K.; Indermuhle, P.; Nock, S.; Wagner, P. Monolayers of Derivatized Poly(L-lysine)-grafted Poly(ethylene glycol) on Metal Oxides as a Class of Biomolecular Interfaces. PNAS 2001, 98, 852-857. doi:10.1073/pnas.98.3.852.

[36] Piedboeuf, M.L.C.; Léonard, A.F.; Reichenauer, G.; Balzer, C.; Job, N. How do the Micropores of Hierarchically Porous Carbon Xerogels Influence their Electrochemical Behavior as Anodes for Lithium-Ion Batteries ? Microporous Mesoporous Mater. 2019, 275, 278-287. doi:10.1016/j.micromeso.2018.08.029.

[37] Rouquerol, J.; Llewellyn, P.; Rouquerol, F. Is the BET Equation Applicable to Microporous Adsorbents? Stud Surf. Sci Catal. 2007, 160, 49-56.doi:10.1016/S0167-2991(07)80008-5.

[38] Dubinin, M. Adsorption in Micropores. J. Colloid Interface Sci. 1967, 23, 487-499. doi:10.1016/0021-9797(67)90195-6.

[39] Jagiello, J.; Ania, C.; Parra, J.; Cook, C. Dual Gas Analysis of Microporous Carbons using 2D-NLDFT Heterogeneous Pore Surface Model and Combined Adsorption Data of $\mathrm{N}_{2}$ and 
$\mathrm{CO}_{2}$. Carbon 2015, 91, 330-337. doi:10.1016/j.carbon.2015.05.004.

[40] Jagiello, J.; Kenvin, J.; Celzard, A.; Fierro, V. Enhanced Resolution of Ultra Micropore Size Determination of Biocharsand Activated Carbons by Dual Gas Analysis using $\mathrm{N}_{2}$ and $\mathrm{CO}_{2}$ with 2D-NLDFT Adsorption Models. Carbon 2019, 144, 206-215. doi: 10.1016/j.carbon.2018.12.028.

[41] Washburn, E.W. Note on a Method of Determining the Distribution of Pore Sizes in a Porous Material. Proc. Natl. Acad. Sci. 1921, 7, 115-116.

[42] Thommes, M.; Kaneko, K.; Neimark, A.V.; Olivier, J.P.; Rodriguez-Reinoso, F.; Rouquerol, J.; Sing, K.S.W. Physisorption of Gases, with Special Reference to the Evaluation of Surface Area and Pore Size Distribution (IUPAC Technical Report). Pure and Applied Chemistry 2015, 87, 9-10. doi:10.1515/pac-2014-1117.

[43] Chen, L.; Deng, J.; Hong, S.; Liang, H. Rapid, Tunable Synthesis of Porous Carbon Xerogels with Expanded Graphite and their Application as Anodes for Li-Ion Batteries. J. Colloid Interface Sci. 2020, 565, 368-377. doi: 10.1016/j.jcis.2020.01.048.

[44] Fu, R.; Chang, Z.; Shen, C.; Guo, H.; Huang, H.; Xia, Y.; Liu, Z. Surface OxoFunctionalized Hard Carbon Spheres Enabled Superiorhigh-Rate Capability and LongCycle Stability for Li-Ion Storage. Electrochim. Acta 2018, 260, 430-438. 10.1016/j.electacta.2017.12.043.

[45] Lee, S.W.; Yabuuchi, N.; Gallant, B. M.; Chen, S.; Kim, B.-S.; Hammond, P.T.; ShaoHorn, Y. High-Power Lithium Batteries from Functionalized Carbon-Nanotube Electrodes. Nature Nanotechnol. 2010, 5, 531-537. doi: 10.1038/NNANO.2010.116.

[46] Kuo, S.-L.; Liu, W.-R.; Kuo, C.-K.; Wu, N.-L.; Wu, H.-C. Lithium Storage in Reduced Graphene Oxides. J. Power Sources 2013, 244, 552-556. doi: 10.1016/j.jpowsour.2013.01.186. 
Table of Contents graphic

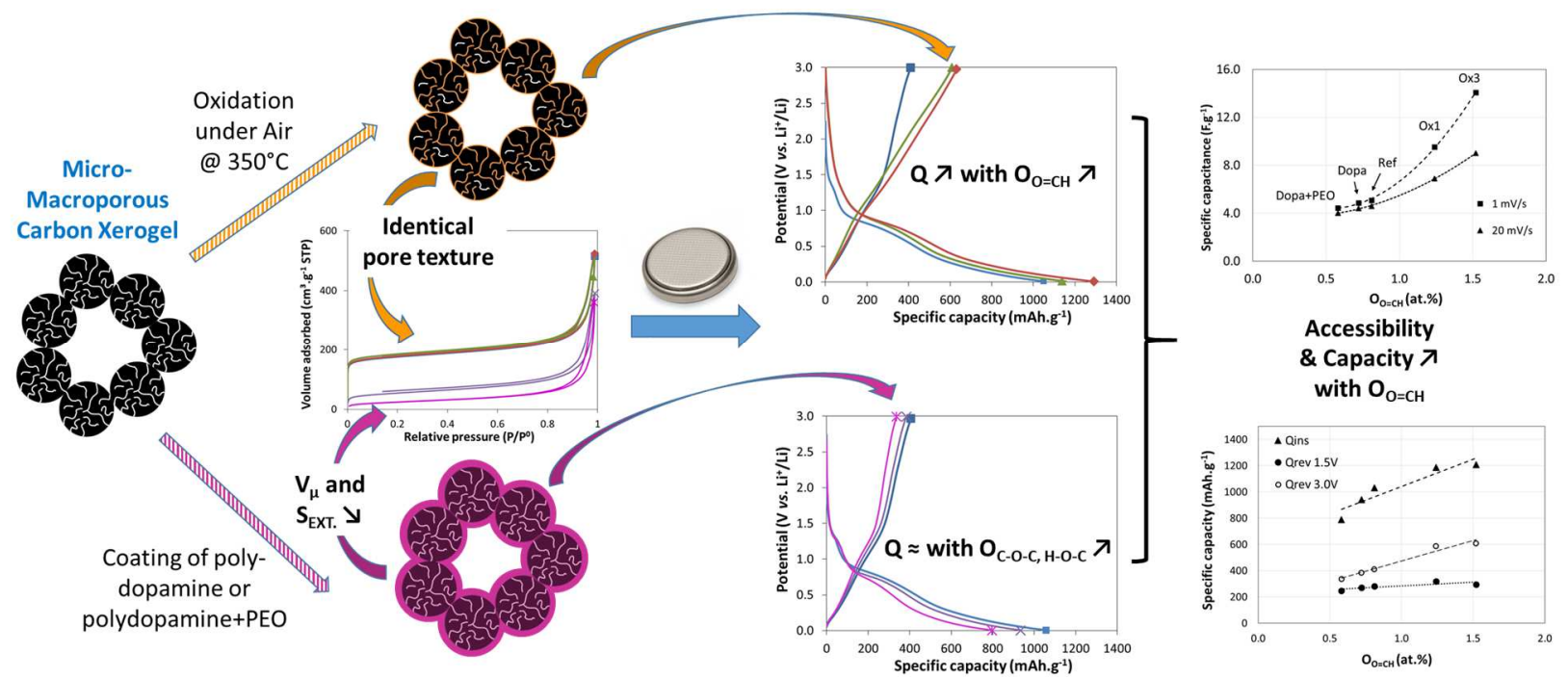


Supplementary information to:

\section{Understanding the influence of surface oxygen groups on the electrochemical behavior of porous carbons as anodes for lithium-ion batteries}

Marie-Laure C. Piedboeuf, Nathalie Job, Abdelhafid Aqil, Yan Busby, Vanessa Fierro, Alain Celzard, Christophe Detrembleur, Alexandre F. Léonard

\section{SI1: Investigation of textural parameters by mercury intrusion porosimetry}

Fig. SI1 shows the mercury intrusion curves obtained for all the studied samples. Table SI1 summarizes the values of total volume of mercury, $V_{\mathrm{Hg}, \mathrm{tot}}$, of pore volume excluding intergranular voids, $V_{\text {Int }}$, and of average pore size, $d_{\text {p,average. }}$

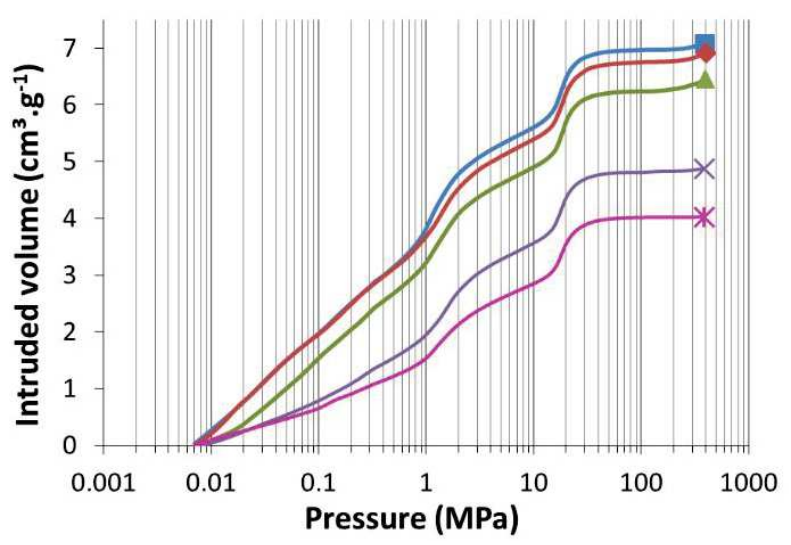

Fig. SI1: Comparison of mercury intrusion porosimetry curves: ( $\square)$ CX-Ref, $(\diamond)$ CX-Ox1, ( $\triangle$ ) CX-Ox3, (×) CX-Dopa and (*) CX-Dopa+PEO.

Table SI1: Textural parameters of carbon xerogels samples determined by mercury intrusion porosimetry.

\begin{tabular}{llll}
\hline Sample & $\begin{array}{l}\boldsymbol{V}_{\mathbf{H g}, \text { tot }^{\mathbf{a}}} \\
\left(\mathbf{c m}^{\mathbf{3}} \cdot \mathbf{g}^{-\mathbf{1}}\right)\end{array}$ & $\begin{array}{l}\boldsymbol{V}_{\mathbf{I n t}} \mathbf{b} \\
\left.\mathbf{( c m}^{\mathbf{3}} \cdot \mathbf{g}^{\mathbf{- 1}}\right)\end{array}$ & $\begin{array}{l}\boldsymbol{d}_{\mathbf{p}, \mathbf{a v e r a g e}} \mathbf{c} \\
\mathbf{( n m )}\end{array}$ \\
\hline CX-Ref & 7.1 & 1.2 & 82 \\
\hline CX-Ox1 & 6.9 & 1.2 & 83 \\
CX-Ox3 & 6.4 & 1.2 & 81 \\
\hline CX-Dopa & 4.9 & 1.1 & 82 \\
CX-Dopa+PEO & 4.3 & 1.0 & 82 \\
\hline
\end{tabular}

${ }^{\text {a }}$ Total $\mathrm{Hg}$ uptake at $\mathrm{P}=400 \mathrm{MPa}$ with an accuracy of $\pm 0.1 \mathrm{~cm}^{3} \cdot \mathrm{g}^{-1}$

${ }^{\mathrm{b}} \mathrm{Hg}$ uptake in the pores of $\mathrm{CX}$ without inter-particle voids in the powder

${ }^{\mathrm{c}}$ Average pore size calculated by the Washburn equation. 
In the case of CX-Ref, two distinct jumps are observed on the mercury intrusion curve as a function of the applied pressure. The progressive increase of volume of mercury at low pressure corresponds to the compaction of powder particles with rising pressure. In the range of medium pressure, a second increase corresponds to the intergranular intrusion of mercury. Finally, at high pressure, a typical intrusion step is observed and corresponds to the penetration of mercury in the macropores of the material.

In the case of the oxidized samples, a slight decrease of the total volume of mercury, $V_{\mathrm{Hg}, \mathrm{tot}}$, is observed, which can be attributed to a modification of the intergranular intrusion and to the compaction of the powder. Indeed, the intrusion volume associated to the macropores only, $V_{\text {Int }}$, remains constant, as does the average pore size value.

A slight decrease of the macropore volume compared to the reference is also observed in the case of the samples that underwent a treatment using dopamine and the dopamine coating followed by the grafting of PEO. Moreover, a decrease of the total volume of mercury is observed in this case, $\mathrm{V}_{\mathrm{Hg}}$, tot This decrease is mainly due to a different compaction of the powder. Indeed, the treatment performed in wet mode leads to the formation of a more compact powder than in the case of chemical vapor deposition. Moreover, a slight decrease of the macropore volume is observed while the average pore size remains constant. These observations suggest that the post-synthesis coatings occur both at the external surface of the particles as well as on the inner part of the macropores. Nevertheless, the different surface treatments obviously do not have any significant influence on the macropore texture of the starting CX material, allowing for the good preservation of the accessibility to the internal macropore surface in each case. 


\section{SI2: Investigation of powder by laser granulometry}

Fig. SI2 compares the final particle size distributions of powder particles which underwent the different treatments.

According to this graph, the different post-synthesis treatments obviously do not affect the particle size distribution of the final powders, for each studied material.

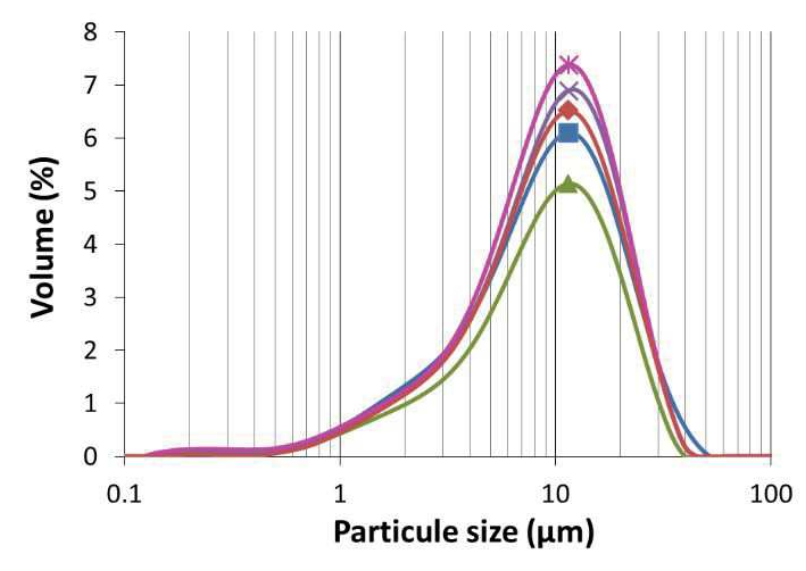

Fig. SI2: Comparison of the final particle size distributions: $(\square)$ CX-Ref, $(\diamond)$ CX-Ox1, $(\Delta)$ CX-Ox3, (×) CX-Dopa and (*) CX-Dopa+PEO.

\section{SI3: Point of zero charge analysis (PZC)}

The point of zero charge of a material is defined as the $\mathrm{pH}$ of the solution, in equilibrium with it, for which the net electric charge resulting of charged functionalities on the surface is equal to zero. This is a commonly used technique to evaluate the chemical environment at the surface of materials. Fig. SI3 presents the point of zero charge (PZC) values obtained for all the studied samples. CX-Ref has a PZC value of 10.2, which is close to the value already reported for a carbon xerogel powder which underwent a pyrolysis step. This value indicates that the surface of the CX is mainly constituted of alkaline functional groups. In the case of CX-Dopa, the PZC decreases to a value close to neutrality (7.5), while the additional grafting of PEO leads to lower PZC value, indicating a slightly acidic surface. No direct correlation can be made between XPS 
results and PZC measurements since, for these materials, nitrogen functional groups are also present, making any comparison impossible.

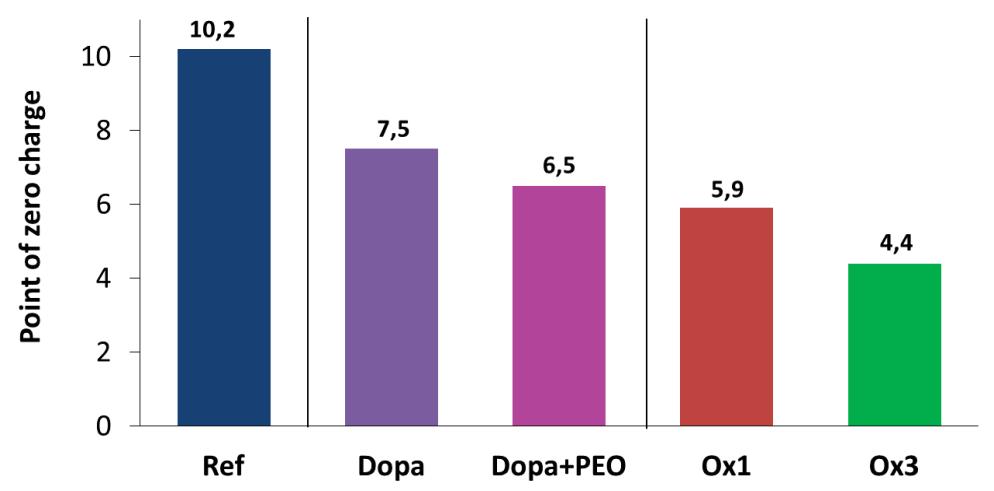

Fig. SI3: Point of zero charge values for CX-Ref and the modified CX powders.

The oxidation treatment under air leads to samples with a much more acidic surface, mainly attributable to the presence of hydroxyl and carboxylic acid groups, which is in line with the XPS analysis.

In summary, the different treatments applied made it possible to obtain materials with PZC values ranging from 10.2 to 4.4 . This will allow for studying the influence of the acido-basic nature of the carbon surface on their electrochemical behavior when used as anodes for Li-ion batteries. 